\title{
CONTROL DEWAR AND VLPC BAYONET CAN PLATFORM CONNECTION DESIGN AND ANALYSIS
}

D0 Engineering Note: $3823.115-E N-467$

July 29, 1997

Andrew Kuwazaki

PPD-ETT D0 Upgrade Group

Approved By

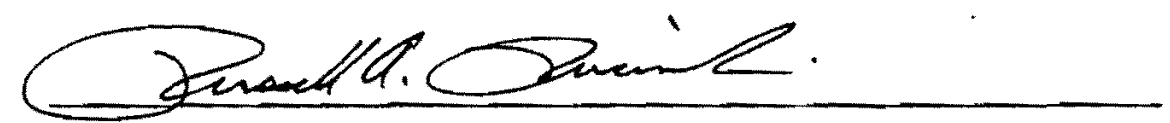




\section{TABLE OF CONTENTS}

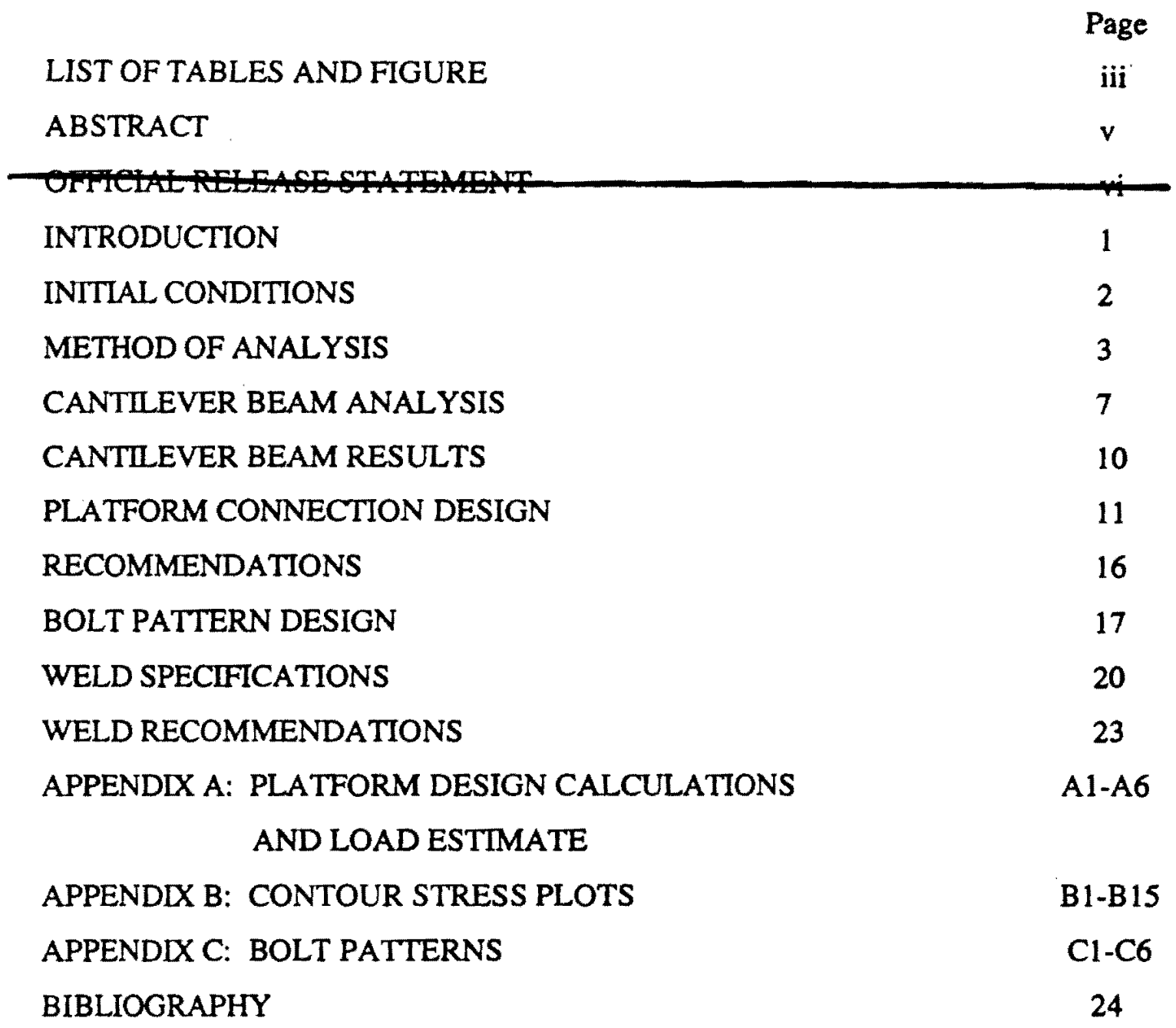




\section{LIST OF TABLES AND FIGURES}

Figure 1. Cantilever Beam 10"x2"xl" with 10,000 in.-lb.

Page

Moment

Figure 2. Cantilever Beam 10"x2"x1" with Extension and Lumped

7 Mass Applied

Figure 3. Assembly of Plate Connection at Nodes 1 and 288

18

Figure 4. Reinforcement Material

19

Figure 5. Assembly of Bracket Connection at Nodes 26 and 313

22

Figure 1-B. Cantilever Beam: Stresses with Lumped Mass and $1-B$ Extensions $(\mathrm{Mz}=10,000$ in-lb.)

Figure 2-B. Cantilever Beam: Stresses without Lumped Mass and Partial Boom Excluded

Figure 3-B. Cantilever Beam: Stresses without Entire Volume on Lumped Mass Side

Figure 4-B. Cantilever Beam: Stresses without Lumped Mass and Extensions

Figure 5-B. Node Connection 288: Lumped Mass and Boom

Figure 6-B. Node Connection 288: Lumped Mass and Partial Boom Excluded

Figure 7-B. Node Connection 288: Lumped Mass, Partial Boom and Fastener Tension Excluded

Figure 8-B. Node Connection 1: Lumped Mass and Boom

Figure 9-B. Node Connection 1: Lumped Mass and Partial Boom Excluded

Figure 10-B. Node Connection 1: Lumped Mass, Partial

Boom and Fastener Tension Excluded

Figure 11-B. Node Connection 313: Stresses with Lumped 
Mass and Boom

Figure 12-B. Node Connection 313: Stress with Lumped

Mass and Partial Boom Excluded

Figure 13-B. Node Connection 313: Stresses with Fastener

13-B

Tension, Lumped Mass and Partial Boom

Figure 14-B. Node Connection 26: Stresses with Lumped

Mass and Partial Boom Excluded

Figure 15-B. Node Connection 26: Stresses with Fastener

15-B

Tension, Lumped Mass and Partial Boom Excluded

Table 1. Moment Results for all Cantilever Beam

Lumped Mass Models

Table 2. Comparison of Moments Results for all

Lumped Mass Models 


\begin{abstract}
The four connections for the control dewar and VLPC bayonet can platform are designed, using finite element analysis, to carry all dead weight and live loads. Based on the loads applied to the platform, two 1 inch thick plates and two $3 / 4$ inch thick brackets made of ASTM A572-Grade 42 are required. The 1 inch thick plate requires a 3/8 inch thick intermediate steel material, between the 8"x4"x1/4" boom and the plate, for load reinforcement as well as weld area reinforcement. Both the plates and the brackets require $3 / 4$ inch steel bolt connections.
\end{abstract}




\section{INTRODUCTION}

The new solenoid, which just arrived from Japan, will be tested while the detector is positioned outside the collision hall to assure that the solenoid operates correctly before it is rolled back into the collision hall. In order for these tests to begin, the proper cryogenics must be made available. The components needed to operate the solenoid are a control dewar, vacuum pump and controllers. All of these components, along with a VLPC bayonet can, have been designated to sit on a platform which will be mounted onto the cryobridge. The cryobridge is essentially a rectangular column that houses cryogenic piping and runs around the perimeter of the detector. The focus of this report is the platform connections.

First, the load estimates, due to the above components, are considered. Second, the platform dimensional outline and the loads, as applied to the platform structure, are presented. Third, the reaction forces and moments, generated by a finite element analysis, are presented for all four connection points. Once these three steps are complete, the platform connection design begins.

The platform connection designs start by first explaining the initial conditions governing the design. Second, the design analysis method is presented. Third, the platform connection design is presented. And finally, the recommendations for the connections, the bolt patterns and the weld calculations are presented. 


\section{INITIAL CONDITONS}

The platform design begins with a load analysis, which is based on the components mounted on the platform as seen in Appendix $A^{1}$. This section of the analysis specifies the platform dimensions and the type of structural material chosen. Page A3 is the dimensional outline of the platform structure, consisting of 2"x 4" 3 3/16" and 4"x 8"x 1/4" rectangular tubing. After these types of tubing were chosen, the loads were distributed as seen on page A4. This model is then entered into the computer and a finite element analysis (FEA) is performed. A finite element analysis is an approximate method for calculating the behavior of the real structure. Points A, B, C, and D on the model are considered the connection points of the platform. The results from the FEA are shown on page A5, where the reaction forces and moments are drawn at all four connection points. In order to maintain continuity with the FEA model, the connection points will no longer be labeled A, B, C, D, but will rather be designated as nodes 1, 26, 313 and 288 due to the meshing process generated by the computer. Page A6 shows the assigned nodes in a simple wireframe sketch and presents the reaction forces and moments in table form at the top of the page.

\footnotetext{
'Appendix A authored by Russell Rucinski, Mechanical Engineer.
} 


\section{METHOD OF ANALYSIS}

The analysis required for the four connections involves analyzing the forces acting on the connections as well as the moments acting on those connections. Therefore, the correct analysis must include both reactions. SDRC I-DEAS 3-D modeling has been chosen to perform the finite element analysis. However, a limitation arises in that this software does not allow for a direct application of a moment onto a solid part. Since I am modeling all four connections as solid parts, I must devise a method that allows me to completely and correctly model my connections. I experimented with numerous elements and meshing techniques in order to find the best analysis method. I also consulted with SDRC. After trying various techniques I found a method that yielded acceptable solutions. This method will be called the lumped mass model. The lumped mass model allows for a moment to be applied to solid and the creation of this lumped mass model is outlined in, "How to Create Moments on a Solid." The outline is written in SDRC IDEAS commands and is presented on the following page.

\section{Lumped Mass Model}

The lumped mass model begins by creating a structure, which is also referred to as a solid part. The structure is then meshed, where the meshing process involves subdividing the structure into nodes and finite elements in order to perform finite element analysis. A finite element is a discrete entity used to subdivide the geometry of the structure and each element is a simple shape such as rectangle or a triangle. The number of finite elements created is determined by the shape and size of the elements. This in turn determines the number and location of the nodes. In a finite element model, nodes are the points where the elements are connected. The nodes are what is needed to continue the development of the lumped mass model.

The moment application process begins by choosing a node on the surface of the structure near the location where the moment is to be applied. The selected node is then copied at some distance away from the structure's surface. The distance chosen is irrelevant since the lumped mass model translates the forces directly to the surface and 
does not require a moment arm length. This new node is designated as the lumped mass and allows for six degrees of freedom(DOF). 


\section{Constraint Elements}

Now that the lumped mass is created, it must be constrained to the surface of the structure. Constraining the lumped mass to the structure allows the moment, which is applied to the lumped mass, to translate to the structure. The leading candidate for constraint is a constraint element. A constraint element connects a single node to a set of nodes and transmits all translational and rotational forces from the single node to the set of nodes chosen. Thus, the constraint element originates from the lumped mass and connects to the elements on the surface of structure, thereby translating the moment acting on the lumped mass to the elements on the surface of the structure. However, in order to transmit the moment from the elements on the surface of the structure to the elements making up the entire structure, the elements on the surface must have six degrees of freedom as well.

\section{Thin Shell Coating}

Thin shell coating has been chosen to transmit the moment from the elements on the surface of the structure to the elements making up the entire structure. The thin shell coating performed on the surface of the structure is done for two reasons. First, it is used to change the elements on the specified surface from three DOF elements to six DOF elements. This allows for the transmission of the moment from the lumped mass through the constraint elements to the elements on the surface, where the elements on the surface can now accept rotational degrees of freedom as well as translational degrees of freedom.

Second, the thin shell coating method provides for the transmission of the moment throughout the entire structure. Since the structure already consists of elements that are similar in size and shape, any force or moment applied to one element will automatically transmit that same force or moment to adjoining elements. Thus, by creating a thin shell coating on the surface of the structure, I am allowing the surface elements to receive force and moment reactions which are in tum transmitted to all the elements in the structure. However, there is one precaution that must be mentioned. 
Precaution

The constraint elements, used to constrain the lumped mass to the elements on the surface of the structure, create a dissimilar mesh between. This occurs because the geometry of the elements on the surface of the structure are different form the geometry of the constraint elements. According to I-DEAS, Creating Elements with Special Techniques, the precaution for joining dissimilar meshes is that the "results for any elements near [this] mesh interface should be suspect." In order to avoid suspect results for elements near the mesh interface, these elements are not selected for display during post processing. 


\section{CANTILEVER BEAM ANALYSIS}

In order to validate the lumped mass method results, I created several cantilever beam models. First I modeled a cantilever beam, as seen below in Fig. 1. The cantilever beam is 10 " $\times 2$ " $\times 1$ " and is made of steel. The left end of the beam is held rigid while a 10,000 in-lb. moment is applied to the other end acting in the z-direction. The resulting bending stress should be a maximum at $15 \mathrm{ksi}$, based on static calculations, where the moment is the force multiplied by the distance and the bending stress is the moment multiplied by the distance from the neutral axis to the outer most fiber divided by the moment of inertia $\left(\sigma_{b}=\frac{M c}{I}\right)$. The results from the finite element analysis (FEA) are $15 \mathrm{ksi}$, which agrees with the calculated bending stress of $15 \mathrm{ksi}$.

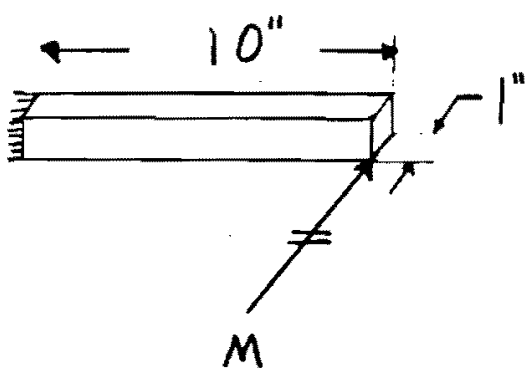

Fig. 1. Cantilever Beam 10"x2"x1" with 10,000 in-lb. Moment Applied

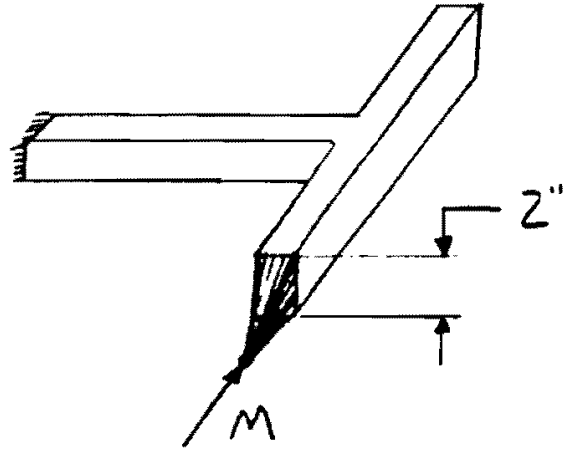

Fig. 2. Cantilever Beam 10"x2"x1" with Extension and Lumped Mass Applied

The second cantilever beam model, Fig. 2, begins with the same dimensions used in Fig. 1, but now there is an additional beam section which extends off the end of the cantilever beam. The additional material allows me to (1) avoid suspect results near the mesh interface, and (2) post process the original cantilever beam section. Now I can constrain the lumped mass, where the 10,000 in-lb. moment in the z-direction is applied, to the surface of the additional material. Thus, when I post process my model to determine the maximum stress, I can chose to post process only a portion of the extended 
material. This allows me to avoid the suspect results completely while still incorporating the effects of the moment applied to the lumped mass.

The results from the lumped mass method as applied to the cantilever beam are shown in Table 1. The first maximum Von Mises stress for the cantilever beam, $15 \mathrm{ksi}$, is the theoretical stress which all the models should predict. I used this theoretical stress as comparison for all the cantilever beam models tested.

I post processed the second model of the cantilever beam which includes the extended beam section and the lumped mass interface. Figure 1-B in Appendix B shows that this maximum Von Mises stress is $29 \mathrm{ksi}$, a stress that is $93.33 \%$ higher than the theoretical stress. This result is precaution mentioned early stating that the "results for any elements near a mesh interface should be suspect." And, as cautioned, the high stresses occur at the mesh interface.

For the third model, I post processed only a portion of the extended beam section, and excluded the lumped mass interface as seen in Fig. 2-B. The maximum Von Mises stress dropped to $24 \mathrm{ksi}$. With this post processing method I have been able to minimize the suspect results near the mesh interface and the maximum Von Mises stress is now only $60 \%$ higher than the theoretical stress. However, the true shape of the cantilever beam must be analyzed as closely as possible. Thus I post processed a fourth model.

The fourth model eliminates the entire extended beam section on the side of the applied moment as seen in Fig. 3-B. The result is a maximum Von Mises stress of 17.6 ksi. This maximum Von Mises stress is only $17.33 \%$ higher than the theoretical maximum stress of $15 \mathrm{ksi}$.

I used a fifth model to determine whether or not the extended beam section on the opposite side of the lumped mass affects the results. Figure 4-B shows the maximum Von Mises stress for the fifth post processed model which post processes only the original cantilever beam. The stress remained the same at a maximum at $17.6 \mathrm{ksi}$. 
TABLE 1. Moment Results for all Cantilever Beam Lumped Mass Models

\begin{tabular}{|l|l|c|c|}
\hline PART & CONDITION & $\begin{array}{c}\text { MAX. VON MISES STRESS } \\
(\mathrm{kSi})\end{array}$ & $\begin{array}{c}\text { \% DIFFERENCE } \\
\text { FROM THEORETICAL }\end{array}$ \\
\hline \multirow{5}{*}{ Cantilever Beam } & & 15 & 0 \\
\cline { 2 - 4 } & 10,000 in-lb moment applied to end of beam & 29 & 93.33 \\
\cline { 2 - 4 } & With Lumped Mass and Extensions & 24 & 60.00 \\
\cline { 2 - 4 } & Without Lumped Mass & 17.6 & 17.33 \\
\cline { 2 - 4 } & Without Elements on Lumped Mass Side & 17.6 & 17.33 \\
\cline { 2 - 4 } & Without Lumped Mass and Extensions & & \\
\hline
\end{tabular}




\section{CANTILEVER BEAM RESULTS}

From the cantilever beam models, I found that the lumped mass model produces a stress that is conservatively higher than that of the theoretical stress value. Therefore, this method will only increase the factor of safety in my design. Thus, I will proceed with the method of adding material to the original design, then applying a lumped mass to the additional material, and finally post processing only the original shape of the platform connections. 


\section{PLATFORM CONNECTION DESIGN}

The design of all four platform connections begins by following the method used for the cantilever beam. The connections are drawn first, and then the additional material is added. I followed the procedure, "How to Create Moments on a Solid," and applied the reaction moments to the lumped mass corresponding to each of the four connections. The connections at nodes 1 and 288 are the plate connections for the platform, and nodes 313 and 26 are the bracket connections for the platform.

\section{Boundary Conditions}

The boundary conditions are comprised of three parts. The first boundary condition applied to the connections is the reaction forces. The reaction forces at the connections are shown in a previous analysis by Russ Rucinski in Appendix A. Page A6 shows a summary of all the reaction forces and moments as they pertain to each node connection.

The second boundary condition specifies which surfaces will be held rigid. The rigid surfaces chosen are the surfaces of the plates and brackets which are in contact with the cryobridge. These surfaces will have no rotation or translation.

The third boundary condition is the application of the $28000 \mathrm{lb}$. minimum fastener tension which is applied to all bolt holes as pertaining to the requirements of the American Institute of Steel Construction (AISC).

\section{Case Scenarios}

The analysis for the four node connections begins with three different case scenarios for each connection. The first case scenario presents the post processing of each connection design including the extended material and the lumped mass. The 
extended material is the rectangular 8 " $\times 4$ " $\times 1 / 4$ " steel tubing, known as a boom. The addition of the boom not only provides a surface to constrain the lumped mass, but is also a true representation of the assembled platform. The second case scenario post processes the connections excluding the lumped mass and a partial section of the boom. The final case presented post processes the connection excluding the lumped mass, a partial section of the boom and the fastener tension. All three case scenarios post processed follow the same case scenarios used to test the cantilever beam discussed previously. Table 2 presents the results of these cases for all four connections and Appendix B presents the stress plots for all the models. Once a maximum Von Mises stress is found, the material selection process can begin. 
TABLE 2. Comparison of Moment Results for all Lumped Mass Models

\begin{tabular}{|c|c|c|}
\hline PART & CONDITION & $\begin{array}{c}\text { MAX. VON MISES STRESS } \\
\text { (ksi) }\end{array}$ \\
\hline \multirow[t]{5}{*}{ Cantilever Beam } & 10,000 in-lb moment applied to end of beam & 15 \\
\hline & With Lumped Mass and Extensions & 29 \\
\hline & Without Lumped Mass & 24 \\
\hline & Without Elements on Lumped Mass Side & 17.6 \\
\hline & Without Lumped Mass and Extensions & 17.6 \\
\hline & D. & (1.7. \\
\hline \multirow[t]{3}{*}{ Node 288} & Lumped Mass and Boom & 4860 \\
\hline & Lumped Mass and Partial Boom Excluded & 81.1 \\
\hline & $\begin{array}{l}\text { Lumped Mass, Partial Boom, and Fastner } \\
\text { Tension Excluded }\end{array}$ & 25.7 \\
\hline & 1. & 2 \\
\hline \multirow[t]{3}{*}{ Node 1} & Lumped Mass and Boom & 4220 \\
\hline & Lumped Mass and Partial Boom Excluded & 81 \\
\hline & $\begin{array}{l}\text { Lumped Mass, Partial Boom, and Fastner } \\
\text { Tension Excluded }\end{array}$ & 17.8 \\
\hline & 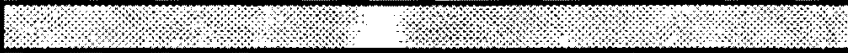 & 2. \\
\hline \multirow[t]{3}{*}{ Node 313} & Lumped Mass and Boom & 6050 \\
\hline & Lumped Mass and Partial Boom Excluded & 81.4 \\
\hline & $\begin{array}{l}\text { Lumped Mass, Partial Boom, and Fastner } \\
\text { Tension Excluded }\end{array}$ & 10.9 \\
\hline & 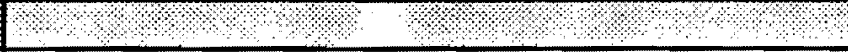 & 2 \\
\hline \multirow[t]{2}{*}{ Node 26} & Lumped Mass and Partial Boom Excluded & 80.7 \\
\hline & $\begin{array}{l}\text { Lumped Mass, Partial Boom, and Fastner } \\
\text { Tension Excluded }\end{array}$ & 9.51 \\
\hline
\end{tabular}




\section{Node Connection 288}

The plate connection at node 288 is modeled first. Fig. 5-B shows the Von Mises stress results for the first scenario; the post processing of the plate including the boom section and the lumped mass. With a maximum Von Mises stress of $4860 \mathrm{ksi}$, this model is clearly beyond the acceptable stress range since the targeted maximum stress should be less than $36 \mathrm{ksi}$. At a maximum stress less than $36 \mathrm{ksi}$ I can utilize ASTM A36 steel which is abundantly available.

The second scenario results, plotted in Fig. 6-B, show a dramatic decrease in the maximum Von Mises stress. The second scenario post processes the plate excluding a portion of the boom and the lumped mass and should be in agreement with the results from the cantilever beam analysis. The stress level dropped as expected, from $4860 \mathrm{ksi}$ to $81.1 \mathrm{ksi}$.. However, the high stress concentration area changed from the mesh interface between the lumped mass and the boom to the fastener tension area around the bolt holes. Since these stresses are compressive stresses and not bending stresses I can neglect their presence when determining the maximum bending stress. Also, if the plate connection was to fail at the bolts, the bolts would fail first during the pre-tension installation period. Therefore, one more scenario must be presented to better approximate the stresses acting on the plate.

The final scenario is the post processing of the plate excluding the boom section on the applied moment side, the lumped mass interface and the fastener tension applied around the bolt holes. Fig. 7-B shows that the maximum Von Mises stress is now only $25.7 \mathrm{ksi}$.

\section{Node Connection 1}

The results presented for node connection 1 are very similar to those for node connection 288 since their geometry is exactly the same. However, due to the locations of the plate connections on the platform, node 1 has a lower maximum Von Mises stress. All three scenario results for node 1 follow the same trends as the scenario results for 
node 288 and the cantilever beam. The maximum Von Mises stresses are 4220, 81, and $17.8 \mathrm{ksi}$ as seen in Figures 8-B, 9-B, and 10-B respectively.

In order to verify the results found for node 1,1 calculated the stress in the plate and compared it to the FEA results. The stress in the plate is mostly due to bending caused by the $16,320 \mathrm{in}-\mathrm{lb}$. moment acting in the $y$-direction. The calculation for the stress in the plate can be followed below.

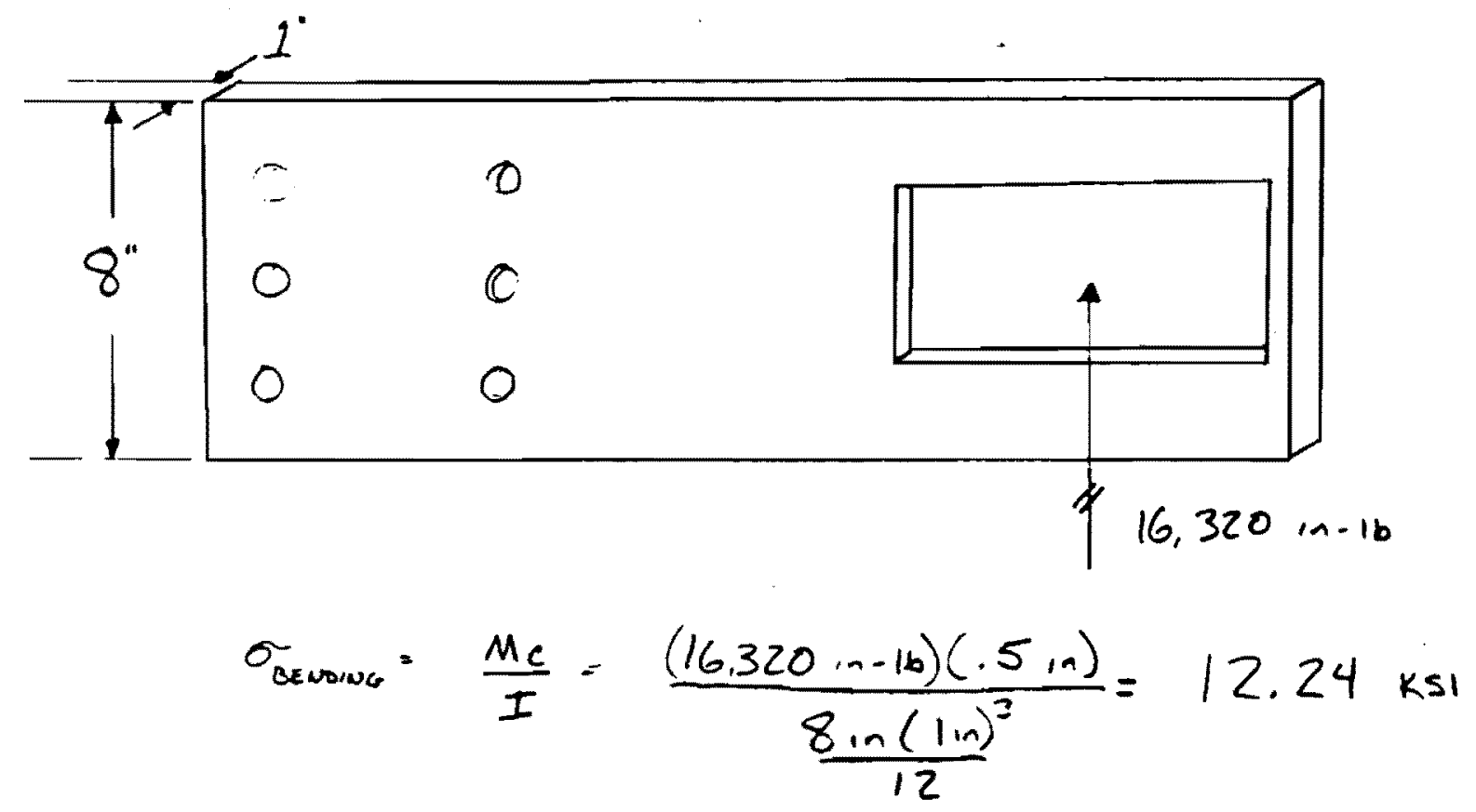

The maximum calculated bending stress for the 8" wide, 1 " thick plate is 12.24 ksi. The FEA model result, as seen in Fig. 10-B for case scenario three, shows a maximum Von Mises stress of $17.8 \mathrm{ksi}$. Both results closely agree, however, the stress comparisons also show that the stresses produced by the FEA will be conservatively high via the lumped mass method.

\section{Node Connection 313 and 26}

Node connections 313 and 26 show similar results to those of node connections 288 and 1 in that the stresses on the bracket are best approximated when post processing the model excludes the lumped mass interface and the additional material. For the third case scenario, the bracket's maximum Von Mises stresses are near $10 \mathrm{ksi}$. 


\section{RECOMMENDATIONS}

The plate and bracket connections are best approximated by the lumped mass method and the material selection is based on the FEA results presented in Table 2. The maximum Von Mises stress for the four connections, excluding the fastener tension, is $25.7 \mathrm{ksi}$ for node 288 . The maximum allowable stress is a combination of bending stress and tensile stress and is 0.66 of the yield strength for a given material per. AISC 1.5.1.4. ASTM A572-Grade 42 steel, or a grade of steel with a higher yield strength, is recommended. The yield stress for this steel is $42 \mathrm{ksi}$ and according the AISC standard for tension and compression on extreme fibers, the maximum allowable bending stress is $27.7 \mathrm{ksi}$. Therefore, the stresses in all four connections are below the allowable when using ASTM A572-Grade 42 steel or greater. 


\section{BOLT PATTERN DESIGN}

The bolt pattems are chosen in accordance with American Institute of Steel Construction standards for minimum spacing and minimum center-to-center distance for each hole. AISC specifies, for minimum spacing in 1.16.4.1, that the minimum distance between the centers of holes "shall not be less than $2-2 / 3 * d$, where $d$ is the nominal diameter of the fastener." In this design, the nominal diameter is .75 inches. Therefore, the minimum allowable distance is 2 inches. I chose to use 2.5 inches as my minimum distance for the design of the 1 "plates(nodes 1 and 288). Also, the minimum allowable edge distance is 1-1/4" according to AISC Table 1.16.5.1. However, in my design I will use an edge distance of 1.5 inches. Both the center spacing distance and the edge distance are chosen to be larger than the allowable minimums in order to increase the reliability of the design.

After choosing the bolt spacing, I analyzed the fastener group using the elastic

method. ${ }^{2}$ Each fastener group is made up of 3/4" bolts, A325 Grade. Here, the allowable tension stress due to bending is $44 \mathrm{ksi}$ and the allowable shear stress is $17.5 \mathrm{ksi}$. The detailed calculations in Appendix $C$ show that the maximum tensile and shear loading will be less than the allowables. For the node 1 and 288 connection, the tension due to bending is $8.7 \mathrm{ksi}$ and the shear stress is $0.213 \mathrm{ksi}$. For node 26 and 313 connection, the tension due to bending is $2.72 \mathrm{ksi}$ and the shear stress is $2.0 \mathrm{ksi}$. The results of these calculations show that the fastener groups can withstand the reaction forces and moments caused by the loads acting on the platform. Therefore, the fastener groups shall be manufactured as designed in Figures 3 and 4, using 3/4" bolts, grade A325.

\footnotetext{
${ }^{2}$ AISC page 4-58 and "Steel Structures, Design and Behavior." $2^{\text {sd }}$ Edition, Section 4-8, by Charles Salmon and John E. Johnson, 1980.
} 

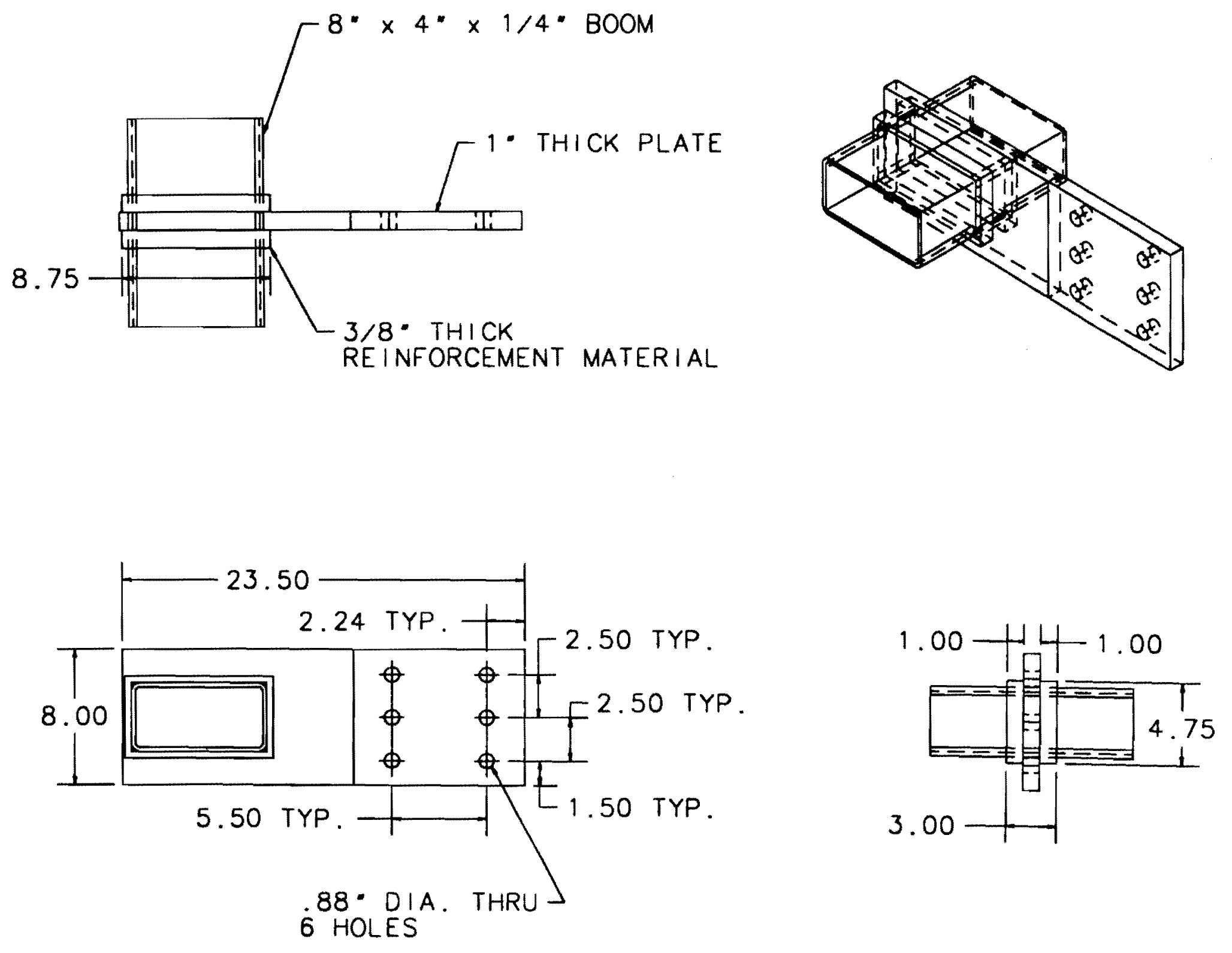

Figure 3. Assembly of Plate Connection at Nodes 1 and 288. 


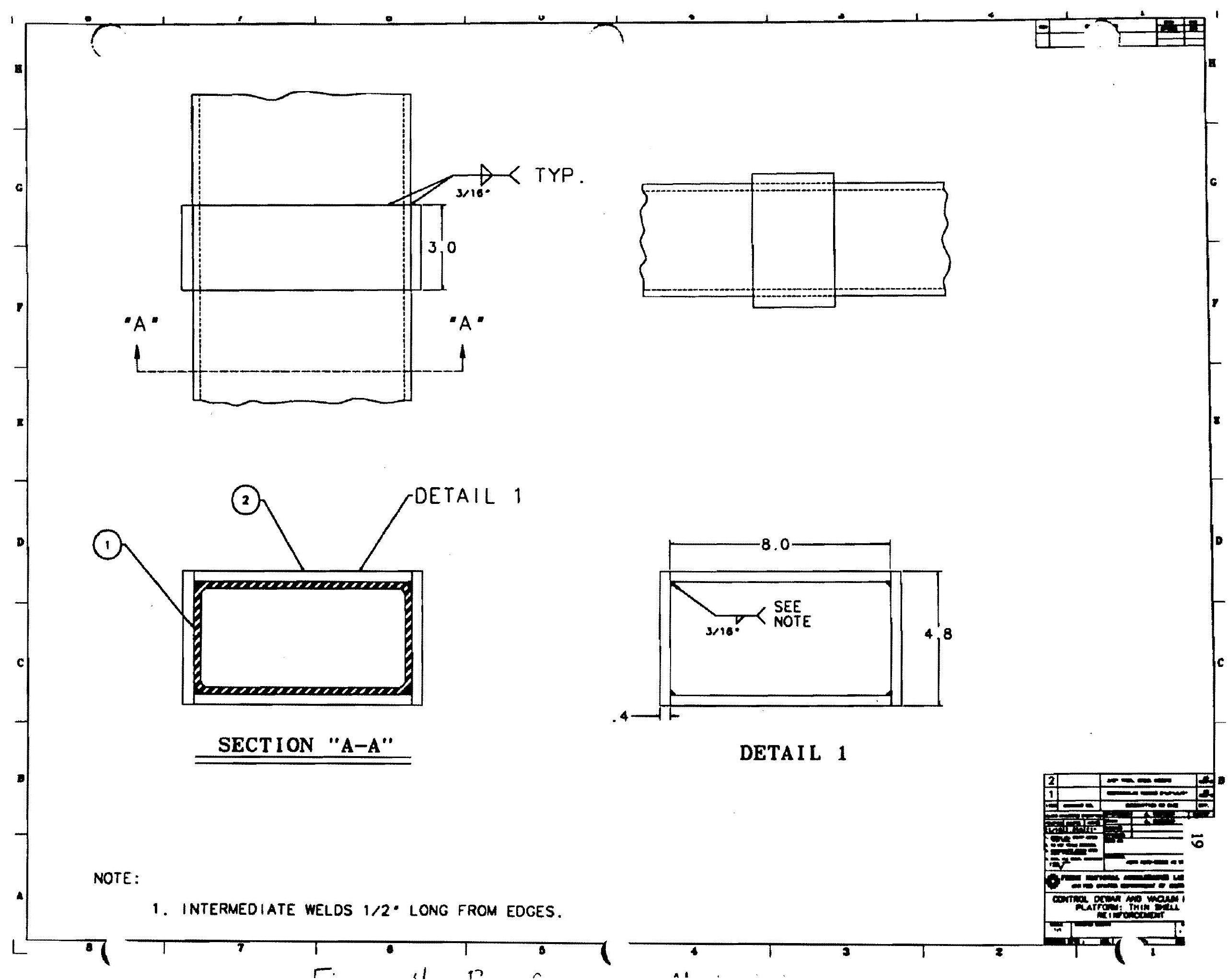




\section{WELD SPECIFICATIONS}

\section{Plate Connection: Nodes 1 and 288}

The two 1" plates for the connections at nodes 1 and 288 are identical in size and shape. Each plate shall follow the dimensions as shown in Fig. 3. According to AISC, the criterion for a fillet weld between two materials is based on the material thickness of the thicker material. However, there appears to be no preference for welding thick material to very thin material. But, there may be limitations for a fillet weld between a 1 " thick plate and the $1 / 4^{\prime \prime}$ thick boom.

Charles G. Salmon and John E. Johnson, in Steel Structures, speak of size limitations which could apply to a weld between 1 " thick and $1 / 4^{\prime \prime}$ thick material. The size limitations apply to the welding process. Since the welding process produces heat energy, the heat energy is mostly absorbed by the thicker of two plates being joined. Therefore, one can see that the thicker material allows for more heat energy dissipation vertically as well as horizontally. Thus, the thicker the plate, the faster the heat energy will be removed from the welding area. This in turn produces lower temperatures at the region of the weld. Since a minimum temperature is required to provide a cohesive connection between the two plates, a weld of sufficient size is needed. In other words, the thickness of the two plates needs to be comparable in size, because, "unless a proper temperature is maintained in the area being welded a lack of fusion will result."

Due to possible limitations of a fillet weld, based on the ratio of material thickness, a solution would be to weld a $3 / 8^{\prime \prime}$ thick material to the $1 / 4^{\prime \prime}$ thick boom, and then weld the $3 / 8$ " thick material to the 1 " thick plate. This approach is beneficial for two reasons. First, this approach provides a reasonable material thickness ratio and thus more adequately provides for the minimum temperature requirements for proper fusion. By welding an intermediate material thickness to the $1 / 4$ " thick boom and to the 1 " thick plate, we avoid the issue of excessive heat dissipation. Secondly, this approach provides reinforcement for the $1 / 4^{\prime \prime}$ thick boom at the point where the plate is welded to the boom. The detail of the $3 / 8^{\prime \prime}$ thick reinforcement material, as welded to the boom, is seen in Figure 4. 
Bracket Connection: Nodes 26 and 313

The two brackets for the connections at nodes 26 and 313 are identical in size and shape. Each bracket will be made of a 1 " thick base plate with the dimensions as shown in Fig. 5. Four individual 3/4" plates or webs, with dimensions shown in Fig. 5, will be welded to the 1 " thick plates as designed. The fillet welds shall be at least $5 / 16^{\prime \prime}$ according to AISC Table 1.17.2A, pertaining to the material thickness of the thicker part joined. The fillet welds lengths shall include the complete contact surface between the $3 / 4$ " webs and the 1 " plate. 


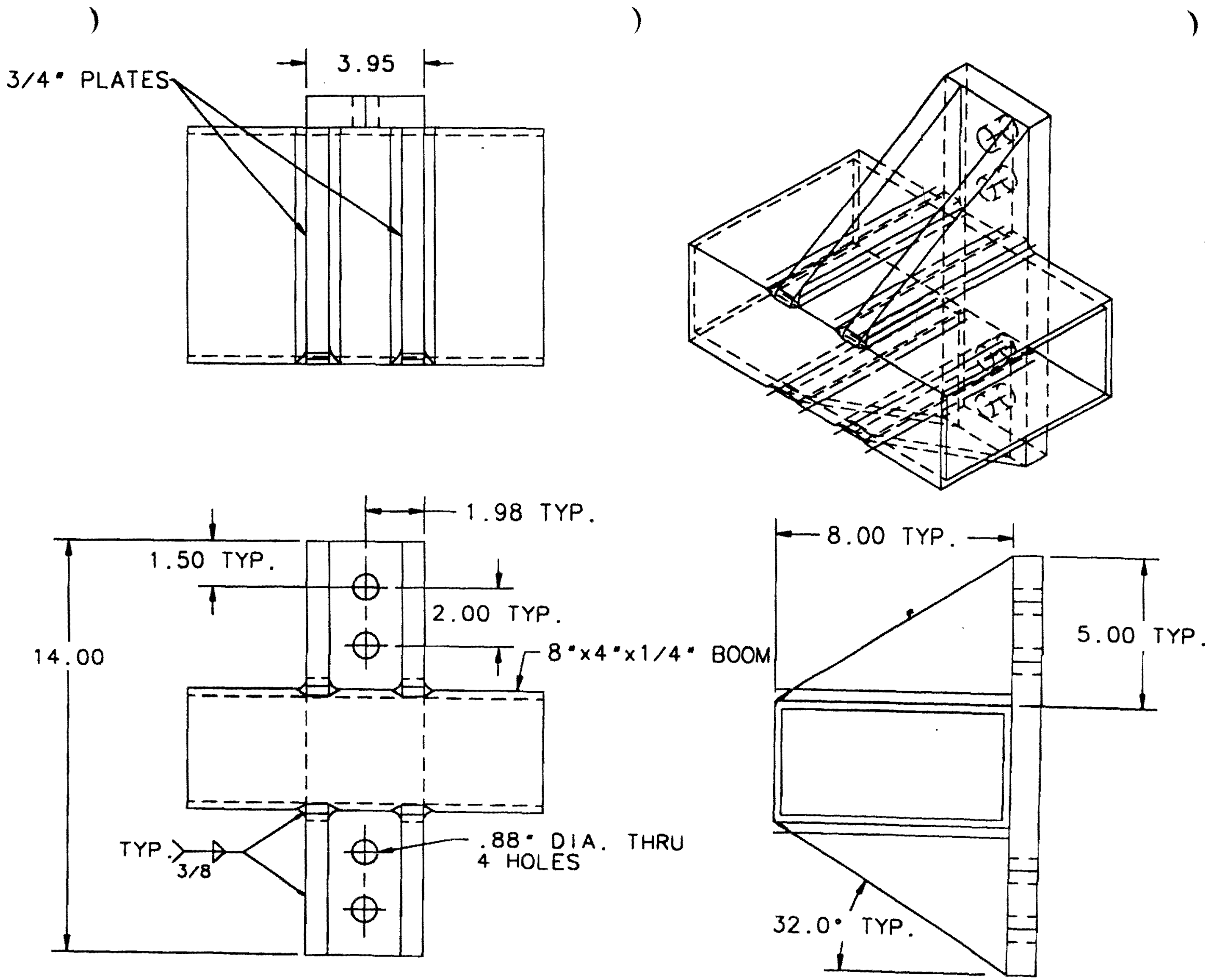

Figure 5. Assembly of Brocket Connection at Nodes 26 and 313 


\section{WELD RECOMMENDATIONS}

The fillet welds between the $3 / 4$ " base plate of the brackets and the $3 / 4$ " webs at nodes 26 and 313 , shall be at least $3 / 8$ inches. The weld shall run around the entire connecting surfaces. The fillet welds concerning nodes 1 and 288 are as follows. The fillet weld between the $1 / 4^{\prime \prime}$ thick boom and the $3 / 8^{\prime \prime}$ thick steel material shall be a $3 / 16^{\prime \prime}$ weld. And the fillet weld between the $3 / 8^{\prime \prime}$ thick steel material and the 1 " thick plate shall be a $3 / 8^{\prime \prime}$ weld. 


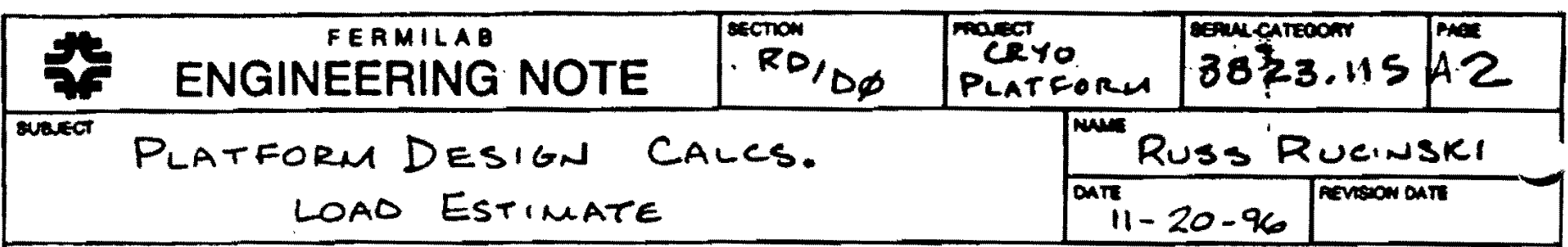

DEAD LOAD OF STRUCTURE

Main Booms : $4 \times 8 \times 1 / 4: 19.0216 / f t \times 10.9 \mathrm{Ft}$. (upper) $=207$

$7.4 \mathrm{Ft}$ (LONER) $=141$

$10.0 \mathrm{ft}$ (oncoum) $=190$

$$
\begin{aligned}
& \text { Rails : } 2 \times 4 \times 3 / 10^{\circ}: 6.87 \mathrm{bt} / \mathrm{ft}, 9.1 \mathrm{Ft} \times 4 \text { (shoes) }=250 \\
& \times 3.3 \mathrm{Ft} \times 2 \text { (t nos) }=45 \\
& \times 12.9 \mathrm{Ft} \times 2 \text { (oincormess) }=177 \\
& \times 8.3 \mathrm{et} \times 3 \text { (vericous) }=171 \\
& \text { Tot }=\overline{1181165}
\end{aligned}
$$

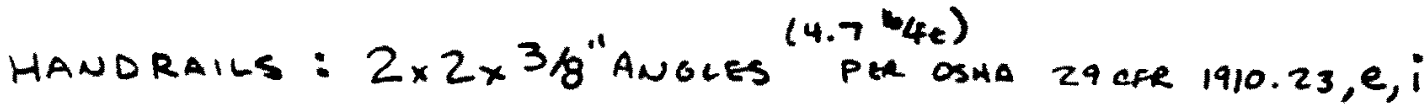

RAILS: $9.1 \mathrm{Ft} \times 8$ S10EO:

3.3 Ft $\times 8$ cuss

- 342

$3.5 \mathrm{FE} \times 6$ VERTical, UPFR PLATFORM ONLT $=99$

$$
\text { TOTAL }=565 \mathrm{~ms}
$$

DECK PLATE; 1/4"THICK $\times 40 " \times 70 "$ UPPER

$40^{\prime \prime} \times 100^{\prime \prime}$ LOWER TOTAL $=482 \mathrm{los}$

TURBO PUMPS CONTROLLERS $=100165 \times 2$ Units $=200165$

ChImney Hangers: $18^{\prime}$ CHIMnet $\times 20^{\mathrm{ros} / \mathrm{FE}}=360 \mathrm{lbs}$

LIVE LOAD $=5 A 42$ PEOPLE $\times 200 \mathrm{lbS}$ EACH PLATFOAM $=800 \mathrm{lbs}$

TOTAL LOADS: UPPER: $1700+500+\frac{1181}{2}+\frac{365}{2}+241+360+400=4074$

LOWER: $\frac{1181}{2}+\frac{565}{2}+241+200+400=1714$

TOTAL $=5788 \mathrm{lbs}$ 


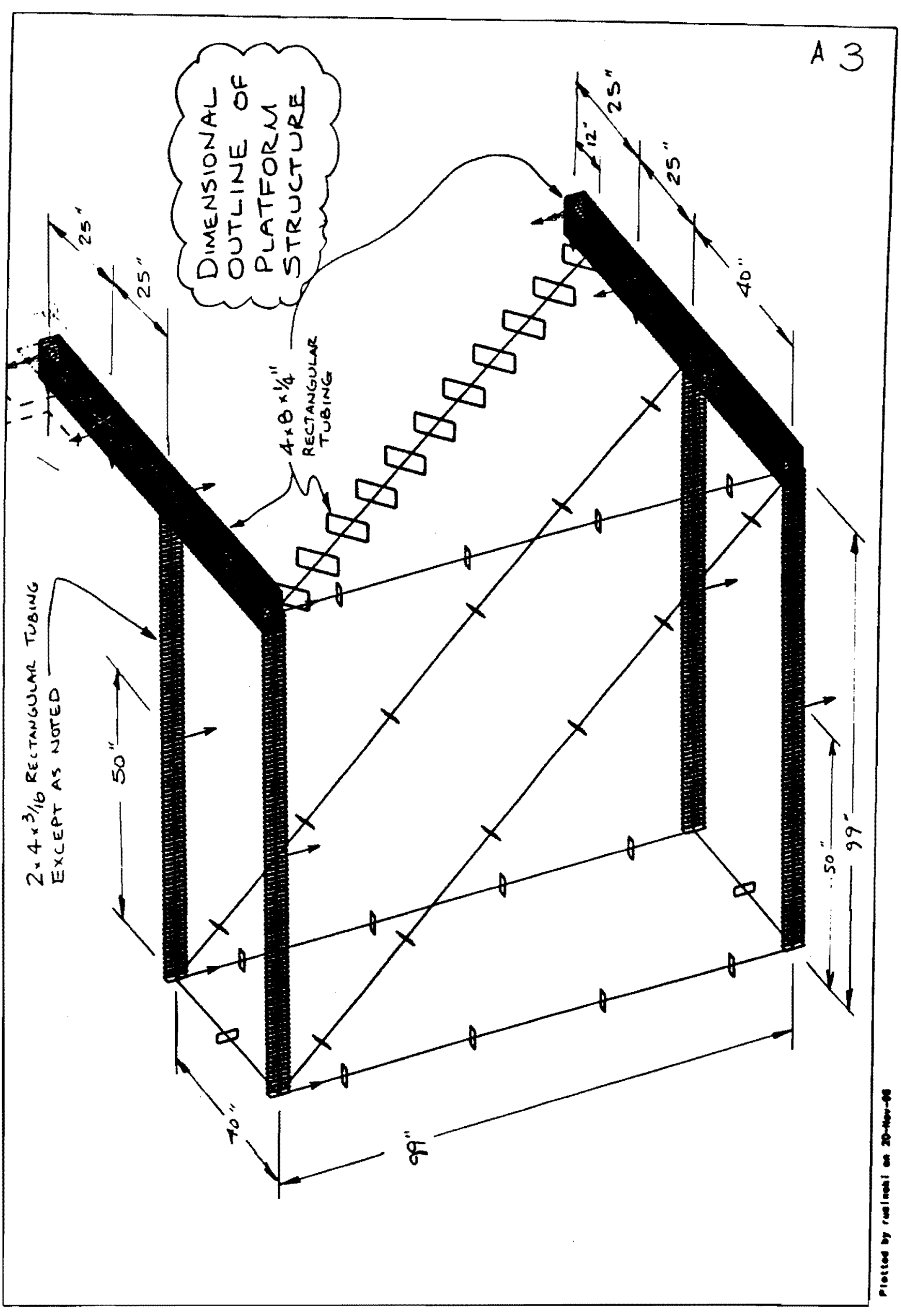




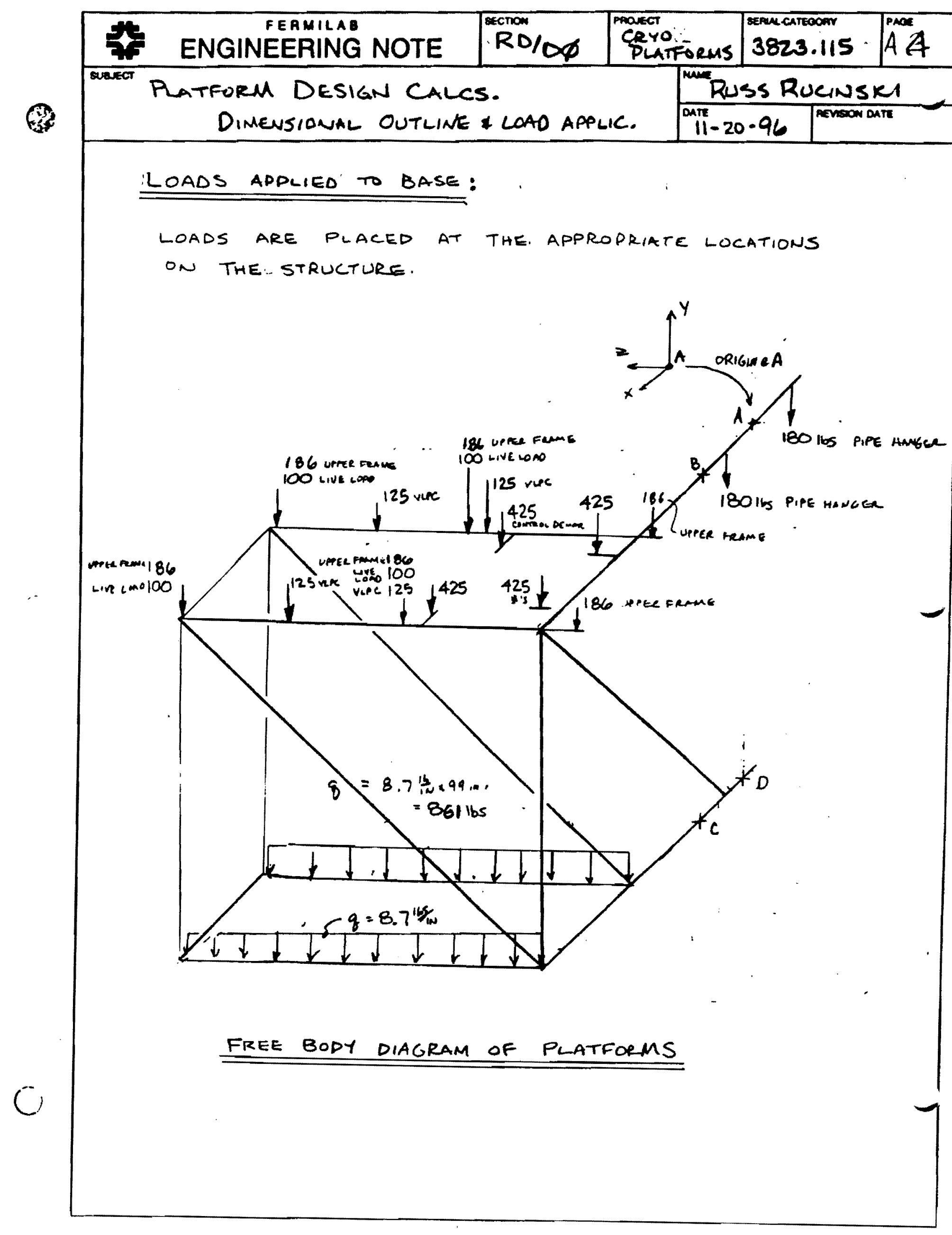




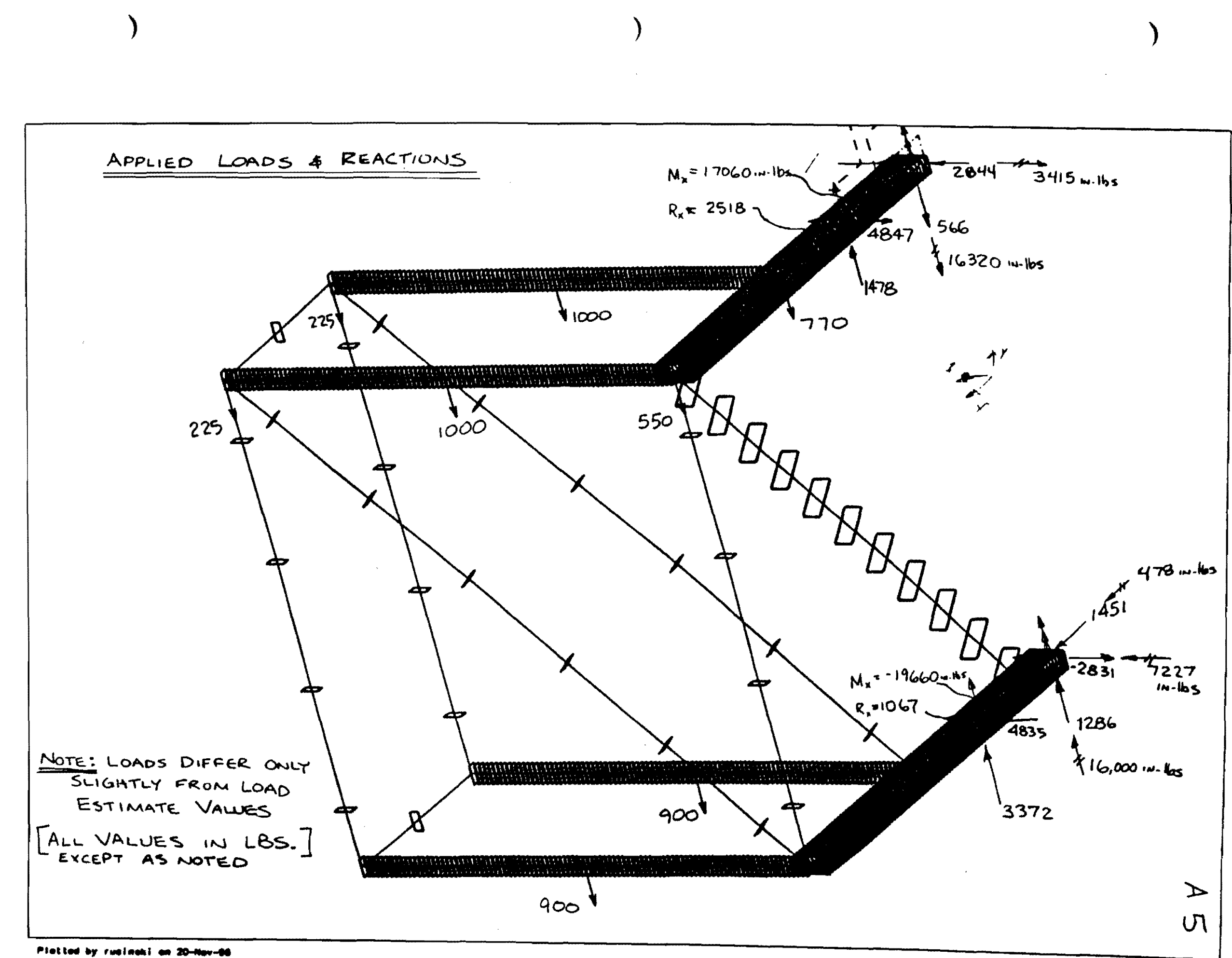

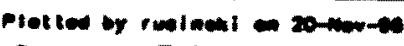

sol ver 3 
Group ID

Result Set

Report Type

Result Type

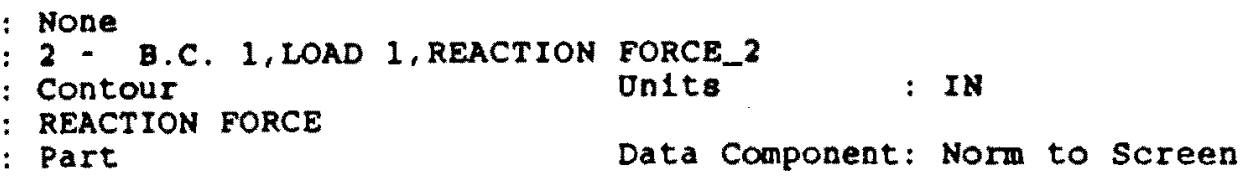

Data Component: Norm to Screen

\footnotetext{
Node Reacti-X Reacti-Y React1-Z React1-RX Reacti-RY React1-RZ

$1 \quad 0.000 E+00-5.655 E+02 \quad 2.844 E+03 \quad 0.000 E+00-1.632 E+04-3.415 E+03$

$26-2.518 E+03 \quad 1.478 E+03-4.847 E+03-1.706 E+04 \quad 0.000 E+00 \quad 0.000 E+00$

$\begin{array}{llllllll}288 & 1.451 E+03 & 1.286 E+03 & -2.831 E+03 & 4.784 E+02 & 1.600 E+04 & 7.227 E+03\end{array}$

$\begin{array}{lllllll}313 & 1.067 E+03 & 3.372 E+03 & 4.835 E+03 & -1.966 E+04 & 0.000 E+00 & 0.000 E+00\end{array}$

cotal $0.000 E+00 \quad 5.570 E+03-4.883 E-04-3.624 E+04-3.194 E+02 \quad 3.811 E+03$

$\begin{array}{ccccccc} & 288 & 313 & 313 & 288 & 288 & 288 \\ \text { Maximum } & 1.451 E+03 & 3.372 E+03 & 4.835 E+03 & 4.784 E+02 & 1.600 E+04 & 7.227 E+03\end{array}$

$\begin{array}{ccccccc} & 26 & 1 & 26 & 313 & 1 & 1 \\ \text { vin1mum } & -2.518 \mathrm{E}+03 & -5.655 \mathrm{E}+02 & -4.847 \mathrm{E}+03 & -1.966 \mathrm{E}+04 & -1.632 \mathrm{E}+04 & -3.415 \mathrm{E}+03\end{array}$

Average $\quad \begin{array}{lllllll}0.000 \mathrm{E}+00 & 9.237 \mathrm{E}+00 & -8.098 \mathrm{E}-07 & -6.010 \mathrm{E}+01 & -5.298 \mathrm{E}-01 & 6.320 \mathrm{E}+00\end{array}$
}
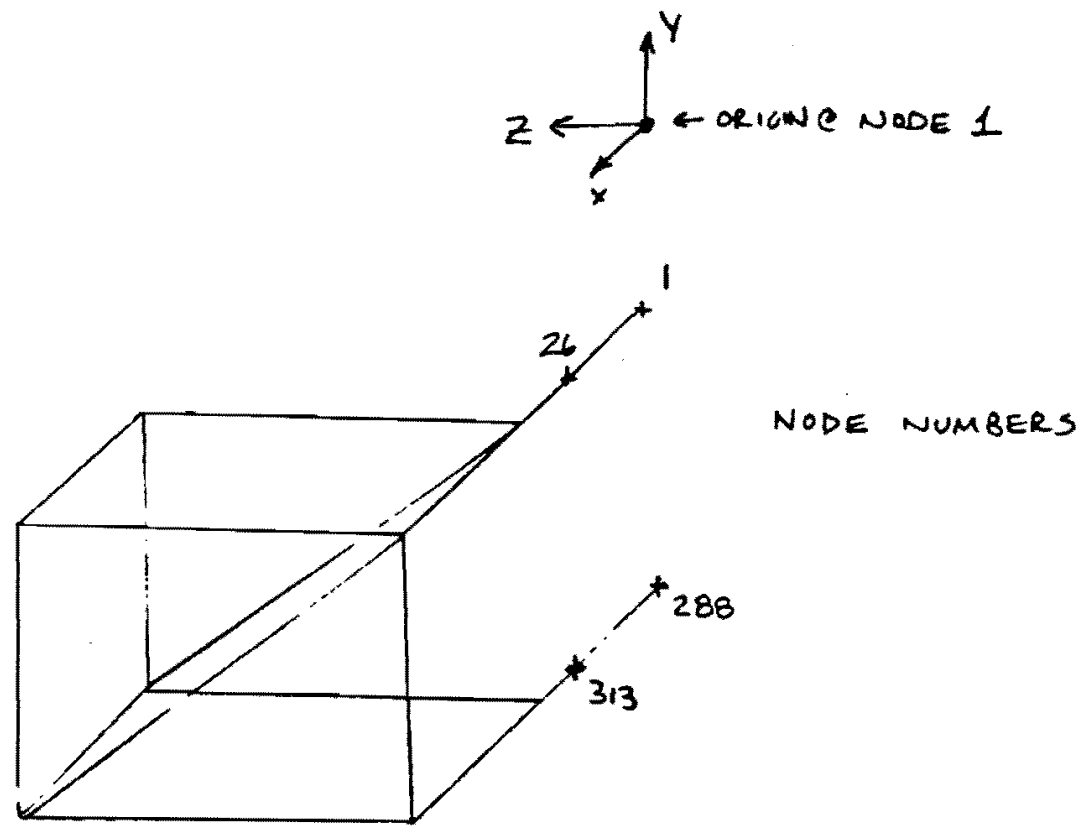

RESTRAINT SPECIFICATIONS

Nodes 1 : $288 ; x, y, z$ translations Rotations fixed

NODES $26: 313 ; x, y, z$ TRANSLATIONS FIXED

$X$ ROTATIONS FIXED

$Y, Z$, ROTATIONS FREE

RESTRAINT SPECIFICATIONS BASED ON 4 BOLT CONNECTION AT NODES 19288,2 BOLTS ALONG YAXISE $26 \% 313$. 


$$
y
$$


Figure 2-B. Cantilever beam: stressés without lumped mass i Partial boom excluded

RESULTS: 2- B.C. 1, LOAD 1, STRESS_2 /aks4d3s7/mg_rucinski/akuwazaki2.mf

STRESS - VON MISES MIN: $2.26 E-01$ MAX: $2.40 E+04$

VALUE OPTION:ACTUAL

FRAME OF REF: PART

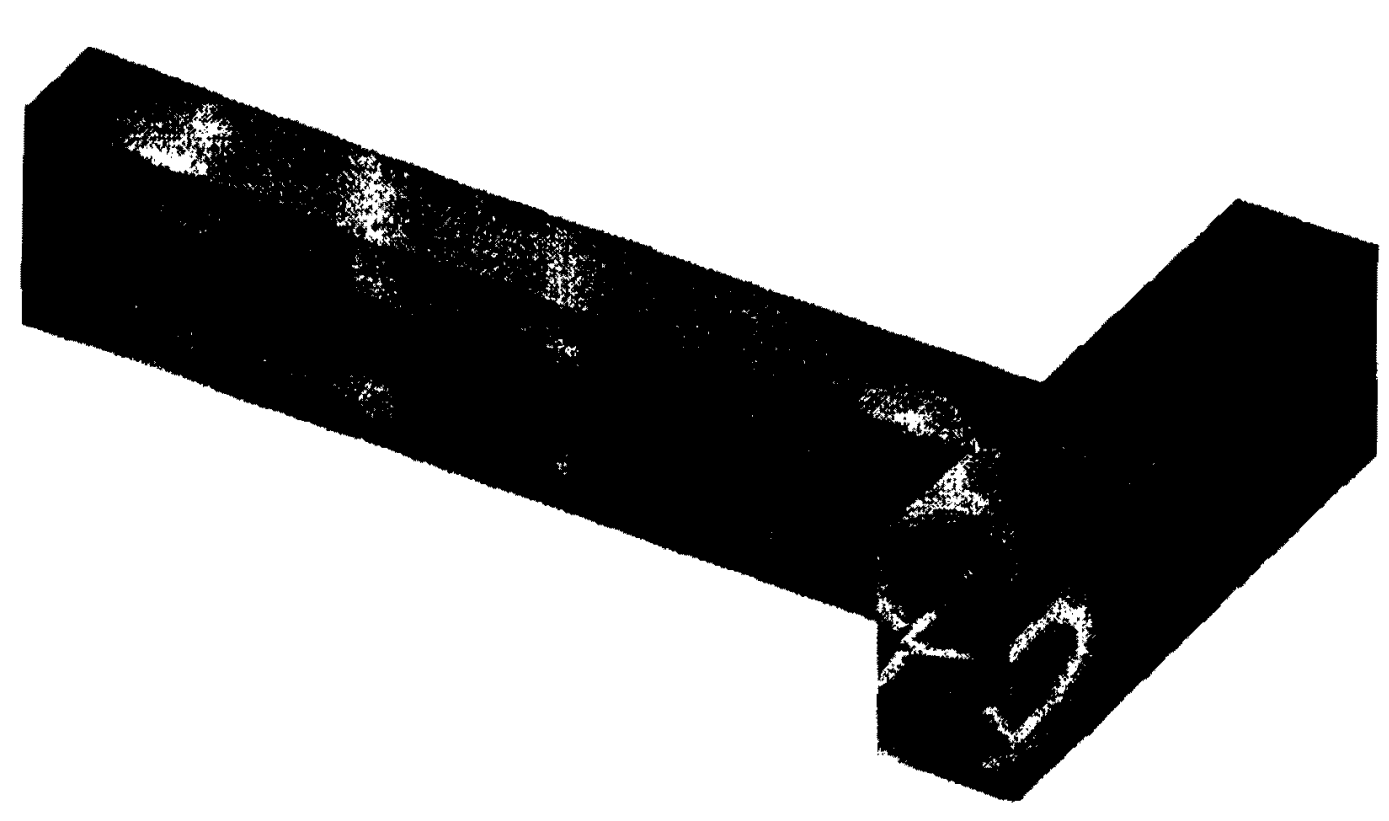

$2.40 E+04$

2. $16 E+04$

1. $92 \mathrm{E}+04$

1. $68 \mathrm{E}+04$

1. $44 E+04$

1. $20 \mathrm{E}+04$

9. $598+03$

$19 \mathrm{E}+03$

4. $79 \mathrm{E}+03$

$2.40 E+03$

2. $26 \mathrm{E}-01 \mathrm{I}$ 
Figure 3-B. Cantilever beam: Stresses without entire volume on lumeed mass side RESULTS: 2- B.C. 1, LOAD 1, STRESS_2 STRESS - VON MISES MIN: 2.26E-02 MAX: $1.76 \mathrm{E}+04$ FRAME OF REF; PART

VALUE OPTION :ACTUAL

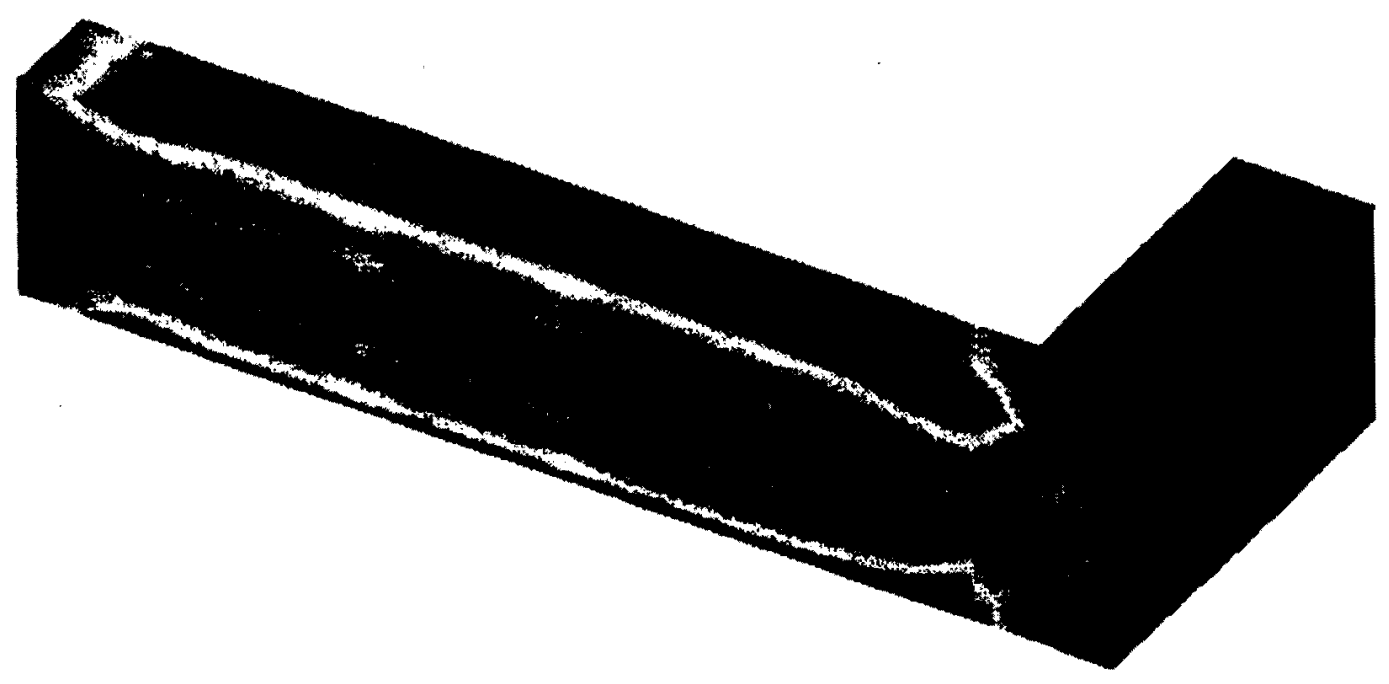

$1.76 \mathrm{E}+04$

1. $58 \mathrm{E}+0.4$

$1 \cdot 41 E+04$

1. $23 \mathrm{E}+04$

$1.06 \mathrm{E}+04$

ด. $81 \mathrm{E}+03$

$7.04 E+03$

5. $28 E+03$

3. $52 \mathrm{E}+03$

1. $76 \mathrm{E}+03$

2. $26 E-01$ 
Figure 4-B. Cantilever Beam: Stresses Without lumped mass \& Extensions

RESULTS: 2-B.C. 1, LOAD 1, STRESS_2

STRESS - VON MISES MIN: $2.26 \mathrm{E}-01$ MAX: $1.76 \mathrm{E}+04$

FRAME OF REF: PART

/dks4d3s7/ma_rucinski/akuwazaki2.mf

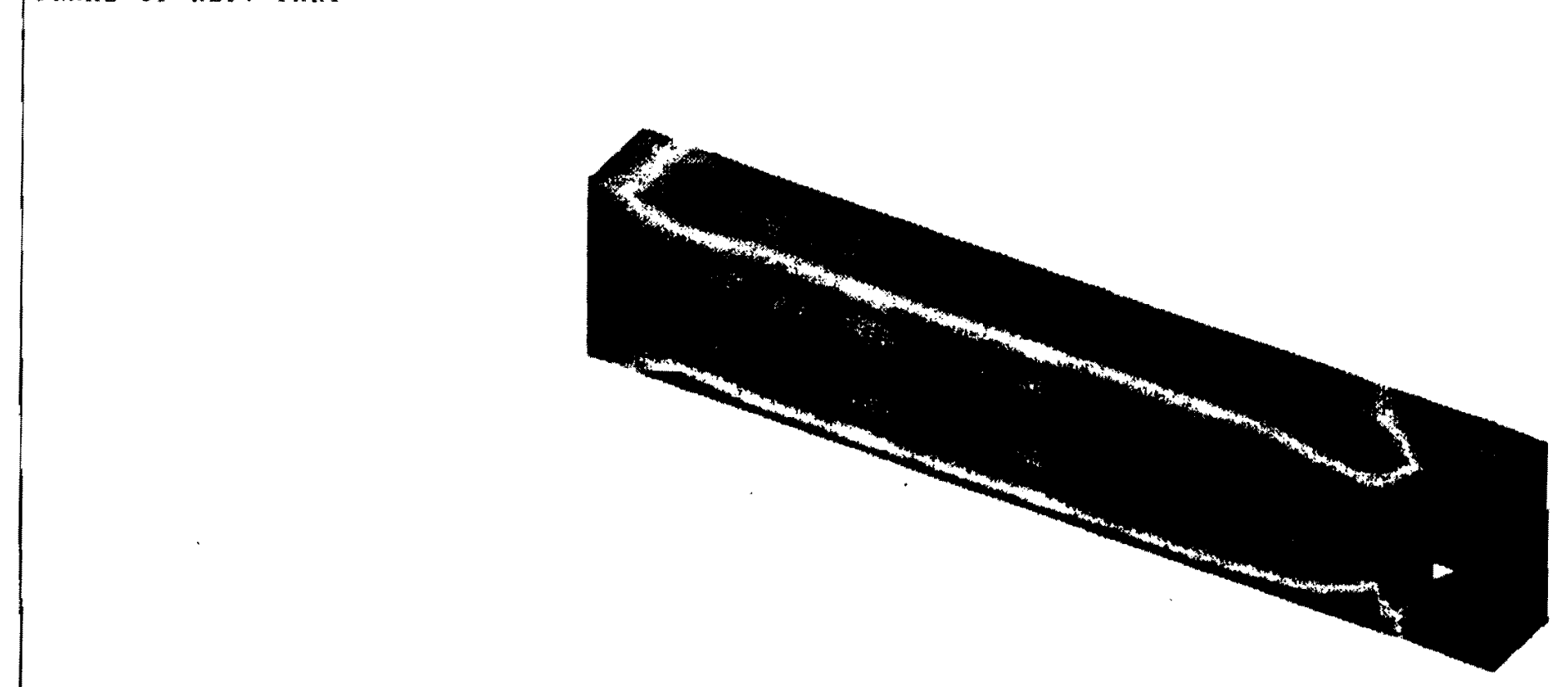

VALUE OPTION:ACTUAL

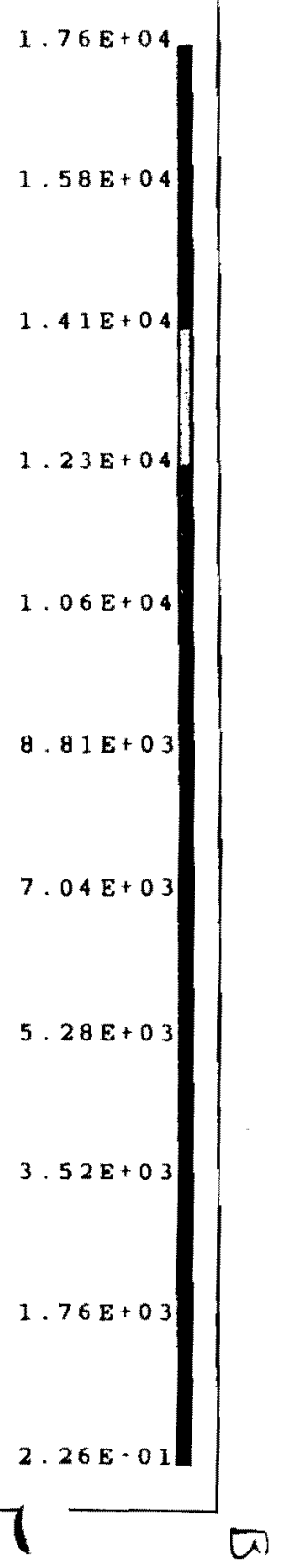


Figure 6-B. Node Connection 288: Lumped Mass \& Partial Boom Excluded

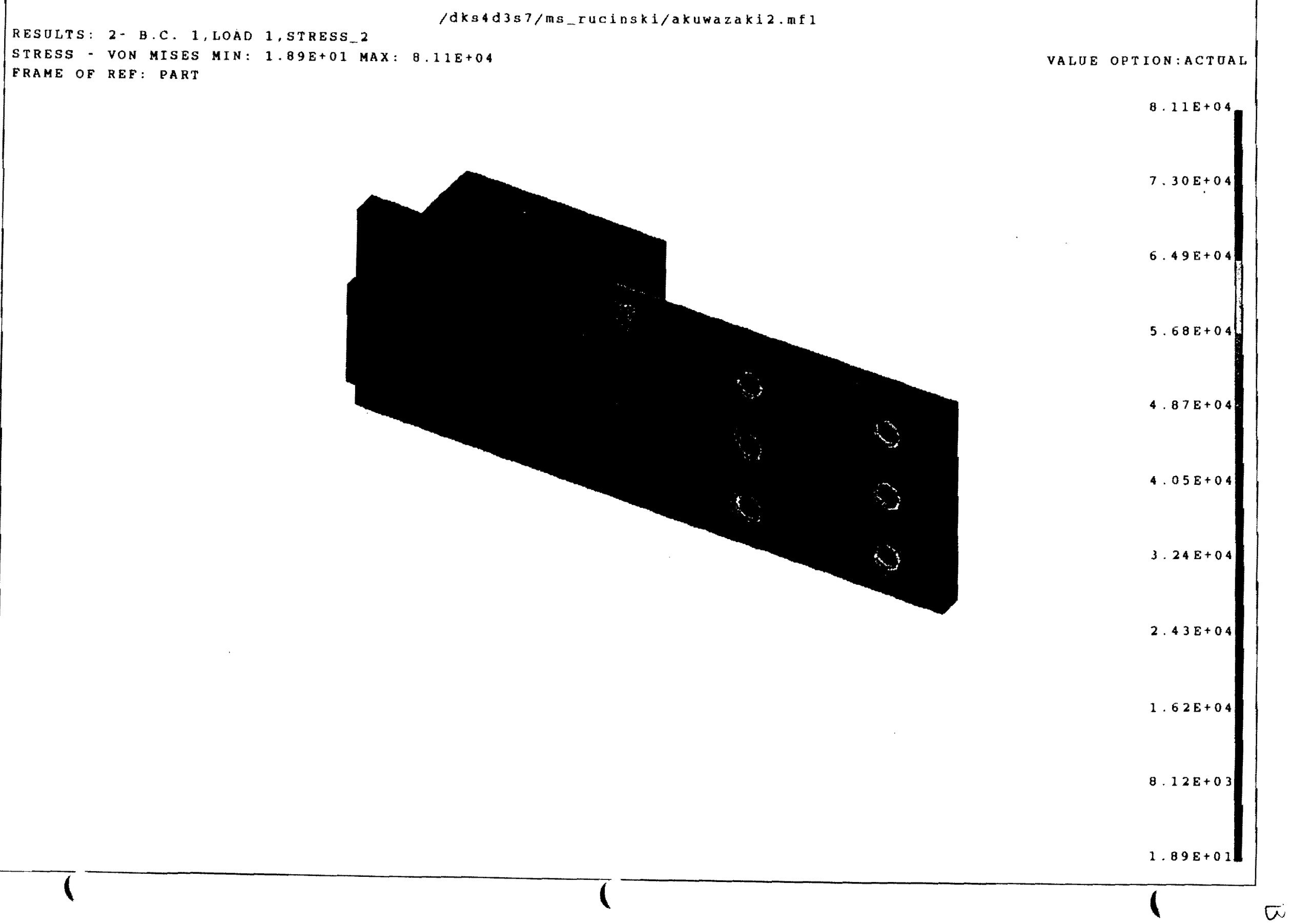


Figure 7-B nOdE CONNECTION 288: LUMPED MASS, PARTIAL bOOM \& FASTENER TENSION EXCLUDED

RESULTS: $2-$ B.C. 1, LOAD 1, STRESS_2

STRESS - VON MISES MIN: 7.89E-02 MAX: $2.57 E+04$

FRAME OF REF : PART

/aks4d3s7/ms_rucinski/akuwazaki2.mf 1

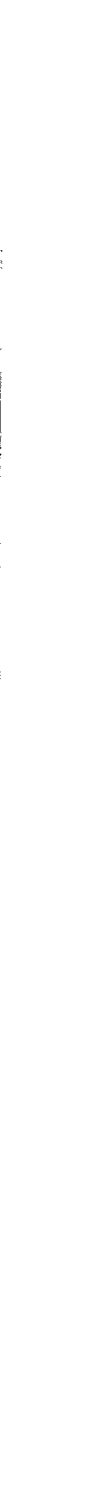

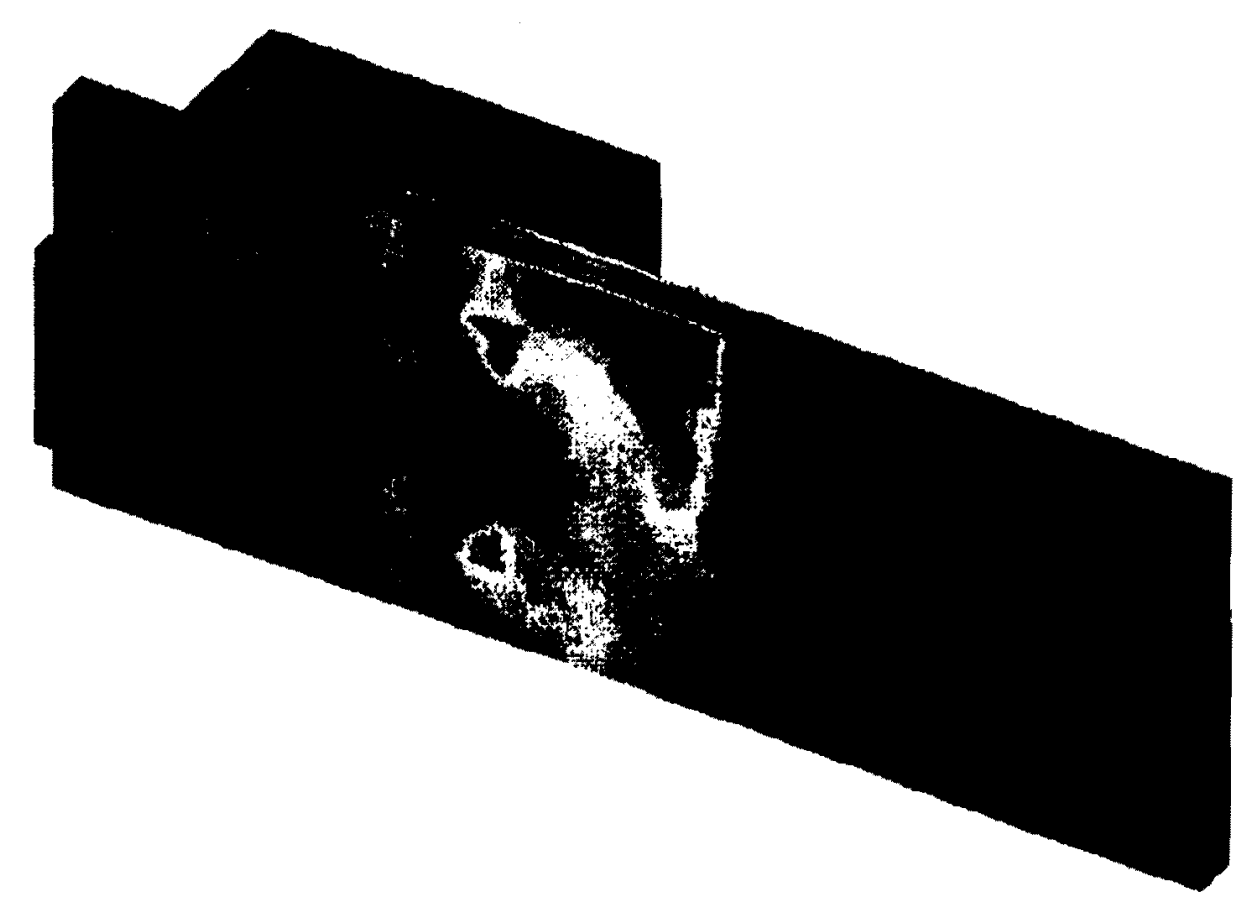

VALUE OPTION : ACTUAL

2. $57 \mathrm{E}+04$

$2.31 \mathrm{E}+04$

$2.05 E+04$

1. $00 \mathrm{E}+04$

1. $54 \mathrm{E}+04$

1. $28 \mathrm{E}+04$

$.03 n+04$

$7.708+03$

5. $13 E+03$

2. $57 \mathrm{E}+03$

$7.89 \mathrm{E}-02$ 
Figune 8-B. NODE CONNECTION 1: LUMPED MASS 2 BOOM

RESULTS: 2- B.C. 1, LOAD 1, STRESS_2

STRESS - VON MISES MIN: $3.58 E+00$ MAX: $4.22 E+06$

FRAME OF REF: PART

$/ d k s 4 d 35 / m_{B}$ rucinski/akuwazaki2.mf 1

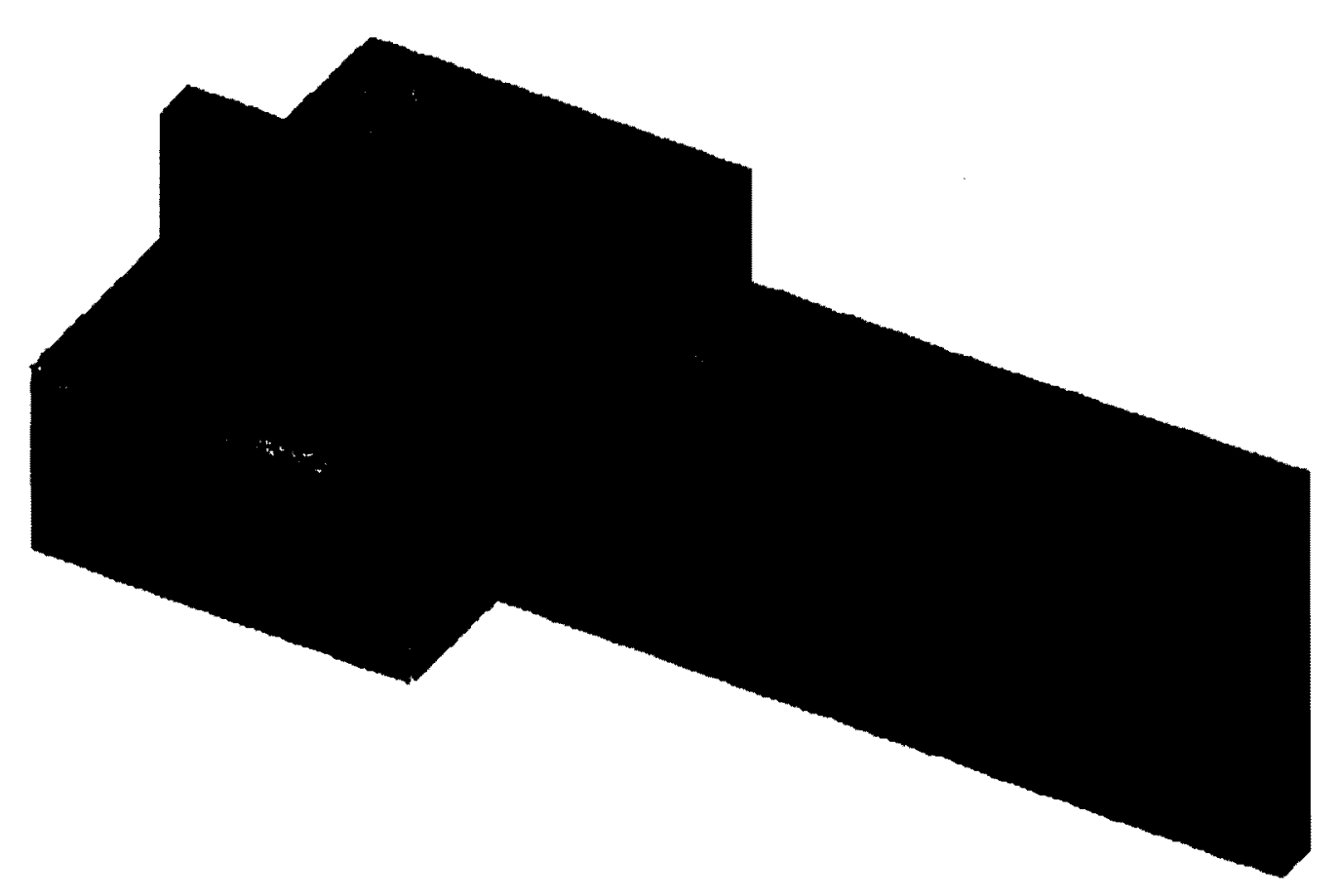

VALUE OPTION:ACTOAL SHELL SURFACE: TOP

$4.22 \mathrm{E}+06$

3. $80 E+06$

3. $38 E+06$

$2.95 E+06$

$2.53 E+06$

2. $11 E+06$

1. $69 \mathrm{E}+06$

$1.27 E+06$

8. $44 E+05$

4. $22 E+05$

$3.58 E+00$ 
)

)

)

Figure 9-B. Node Connection 1: Lumped Mass \& Partial Boom Excluded

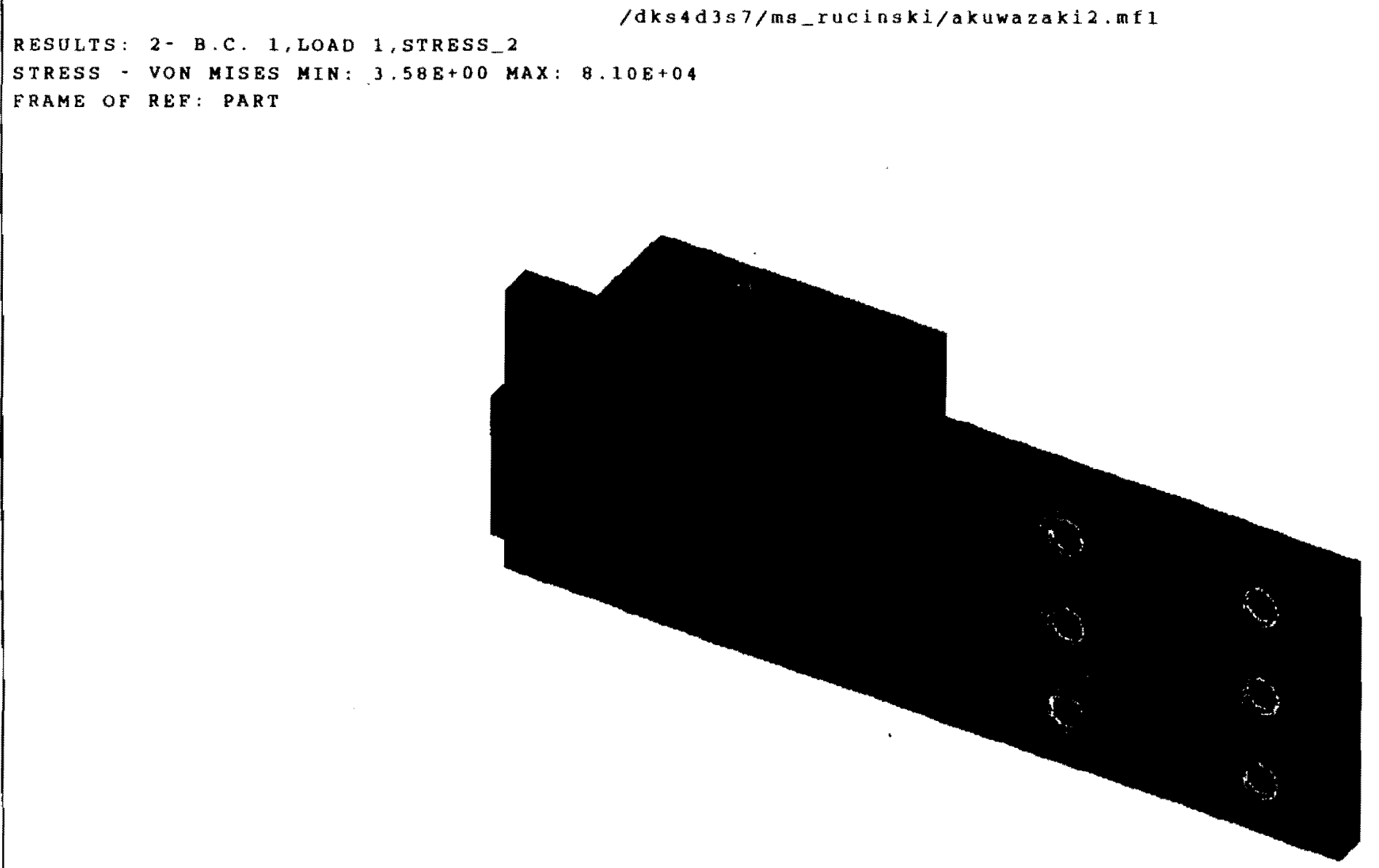

VALUE OPTION: ACTUAL

$0.10 \mathrm{E}+04$

$7.29 E+04$

$6.4 B E+04$
$4.67 E+04$
$4.05 E+04$
$3.24 E+04$
$2.43 E+04$

1. $62 \mathrm{E}+04$

Q. $11 E+03$

$3.58 \mathrm{E}+00$

a 


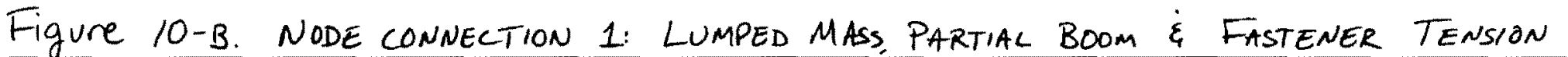

/dks4d3g7/ms rucinski/akuwazaki2.mfi

RESULTS: 2- B.C. 1, LOAD 1, STRESS_2

STRESS - VON MISES MIN : $9.34 \mathrm{E}-02$ MAX: $1.78 \mathrm{E}+04$

ERAME OF REF: PART

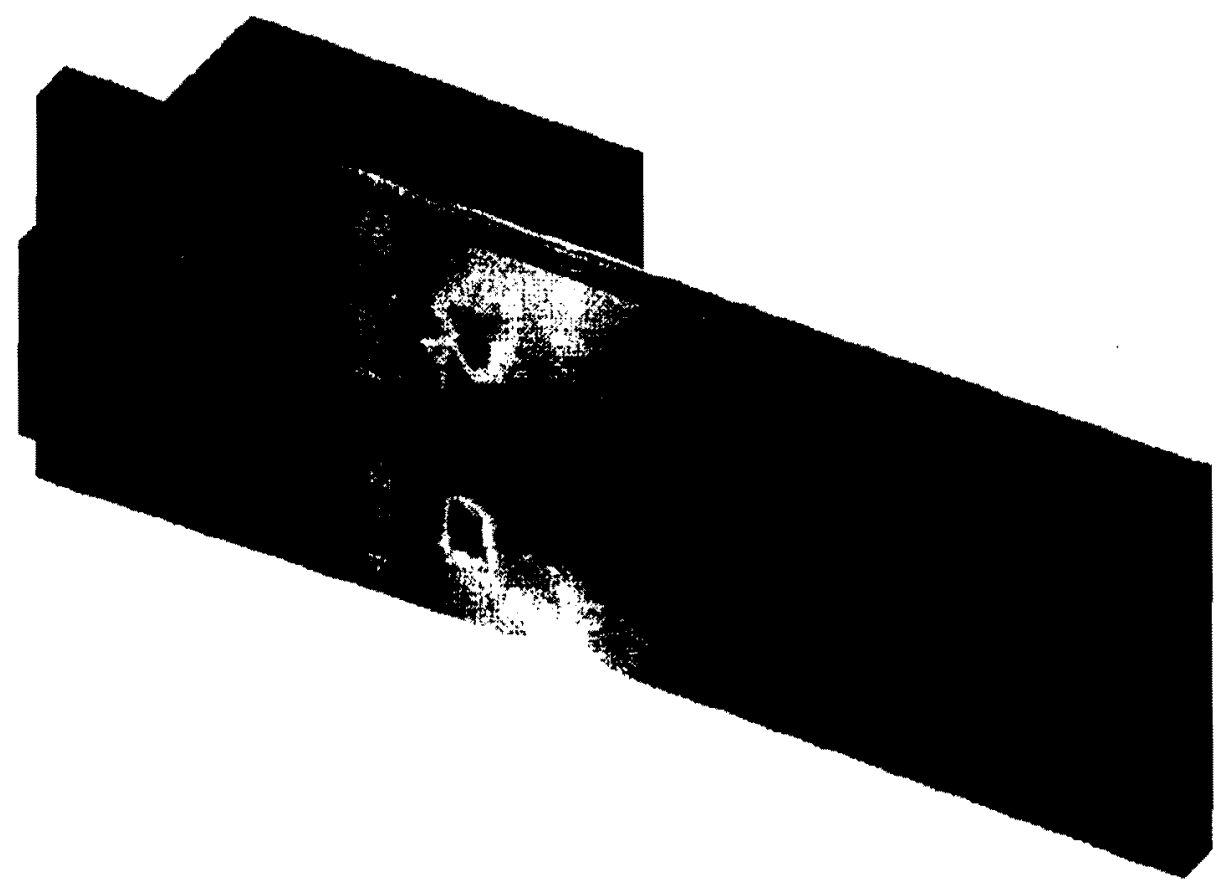

VALUE OPTION:ACTUAL

1. $78 E+04$

$1.60 \mathrm{E}+04$

$1.42 E+04$

1. $25 \mathrm{E}+04$

$1.07 \mathrm{E}+04$

8. $90 \mathrm{E}+03$

$12 E+03$

$34 E+03$

$36 \mathrm{E}+03$

$1.78 E+03$

$9.34 \mathrm{E}-02$ 

Figure 12-B. NODE CONNECTION 313: STRESS WITH LUMPED MASS \& PARTAL BOOM EXCLUDED

RESULTS: $2-$ B.C. 1, LOAD 1, STRESS_ 2

STRESS - VON MISES MIN: $6.87 \mathrm{E}+01$ MAX: $8.14 \mathrm{E}+04$

DEFORMATION: 1- B.C. 1, LOAD 1,DISPLACEMENT 1

DISPLACEMENT - MAG MIN: $0.00 E+00$ MAX: $8.01 E-03$

FRAME OF REF: PART

VALDE OPTION : ACTUAL

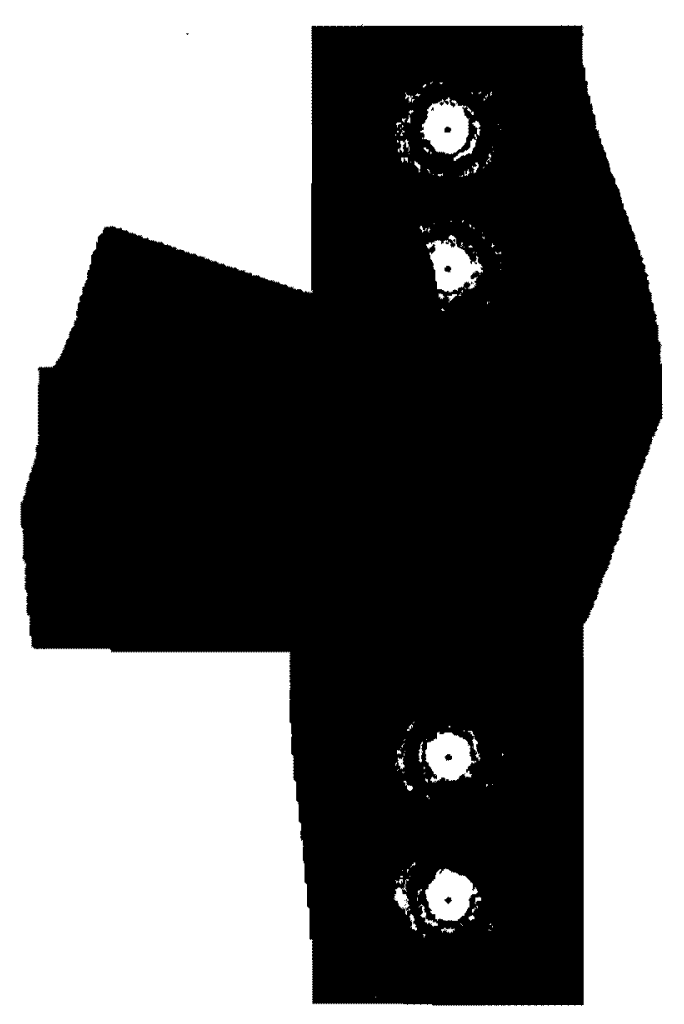

8. $14 \mathrm{E}+0$

7. $32 E+04$

$6.51 E+04$

$5.70 \mathrm{E}+04$

4. $89 \mathrm{E}+04$

$4.07 E+04$

3. $26 E+04$

$2.45 \mathrm{E}+04$

1. $63 \mathrm{E}+04$

8. $20 \mathrm{E}+03$

$6.87 E+010$ 



$$
4
$$



APPENDIX C

A. KUWAZAKI

41

CI

USE $3 / 4^{\circ}$ BOLTS, A3Z5 GRADE

$A_{b}=.4418 \mathrm{in}^{2}$

FROM AISC, PART 4, TABLE 1-4:

$$
F_{t}=44 \mathrm{ksi}
$$

ALLoWABLE LOAD $=194 \mathrm{kSI}$ (TENSION)

TABLE: $-c:$

$$
\begin{aligned}
& F_{Y S}=92 \mathrm{ks} \\
& \left.F_{U S}=120 \mathrm{ks}\right) \\
& P_{\text {Roof }} 1040=85 \mathrm{ks} 1
\end{aligned}
$$

TABLE, ID:

$F_{v}=17.5 \mathrm{ks} \quad(s+24 R)$

ALe ON COAD $=7.7 \mathrm{kPS}$

NODE 2

PER AIS TABLE 1.6 .3 COMBINED TENSION \& SHEAR

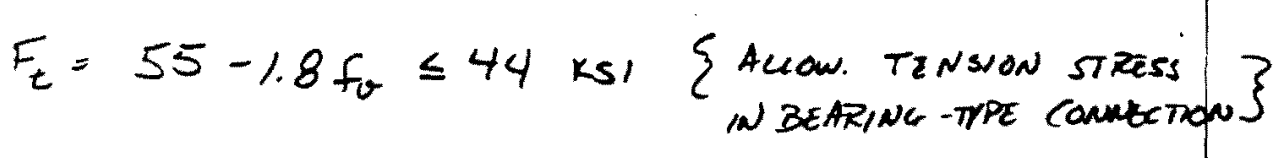
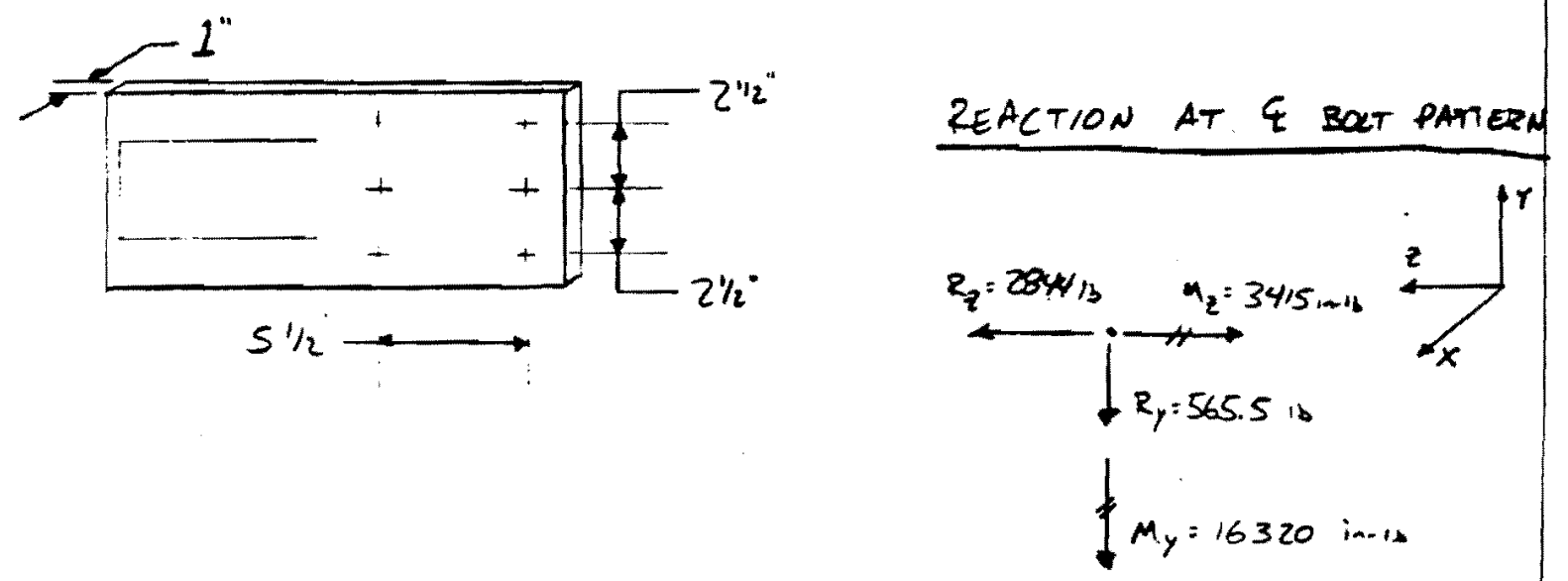

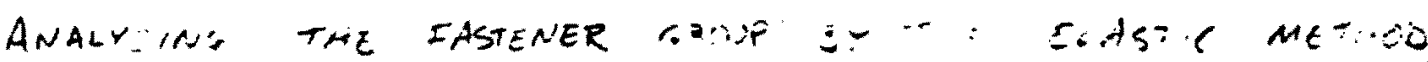

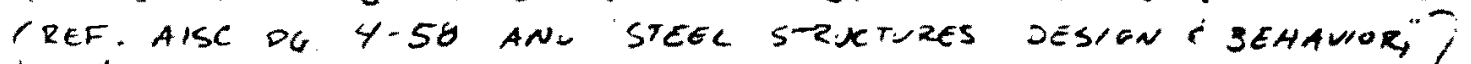

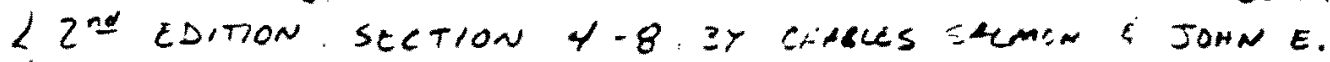
(JOHNSON, 1980

if.

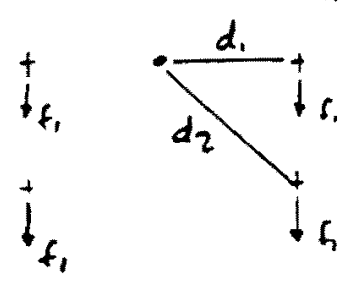


A. Kunazat

REACTION Ry (DIRECT SHEAR):

$$
f_{1}=\frac{R_{y}}{6}=\frac{565.5 \mathrm{~b}}{6}=94.25 \mathrm{~kb} ; f_{\text {ste ne }}=\frac{94.25 \mathrm{~kb}}{.4418 \mathrm{~m}^{2}} \cdot 213 \mathrm{ps}
$$

TENSION FROM BENDING CONSIDERING inITIAL TENSION (a IG "steEL...")

INITIAL BEARING PRESSURE:

$$
\begin{aligned}
f_{b i}=\frac{\sum T_{i}}{b d} ; \quad T_{i} & =28000 \mathrm{lb}(4 / S C \text { TABLE 1.23.5) } \\
\text { PRETENSION LOAD } & b \\
b & \equiv \text { PLATE WIDTH E } 8 \mathrm{iN} \\
d & \equiv \text { PLATE LENGTH } 8 \mathrm{iN}
\end{aligned}
$$

$$
f_{b i}=\frac{28000 \mathrm{~kb}(6 \mathrm{bols})}{(8, \mathrm{~N})(8 \mathrm{~N})}=2.625 \mathrm{ks}
$$

TENSILE STRESS

$$
f_{t b}=\frac{6 M}{b d^{2}}=\frac{6(16320, \cdots-1 s}{(8.0)(8, v)^{2}}=192 \mathrm{ps}
$$

fo SHOW LD NOT EXCEED for IF COMPRESSION BETWEEN THE PIECES IS TO REMAIN AT THE TOP

$$
\begin{aligned}
& f_{E b}=192 \text { PSI }<f_{b i}=2625 \text { ps } \\
& T_{\text {NET }}=f_{t b} \text { bP }=(192 \mathrm{Asi})(8 . \mathrm{N})(2 \mathrm{1} / 2, \mathrm{~N})=3840 \mathrm{lb}
\end{aligned}
$$

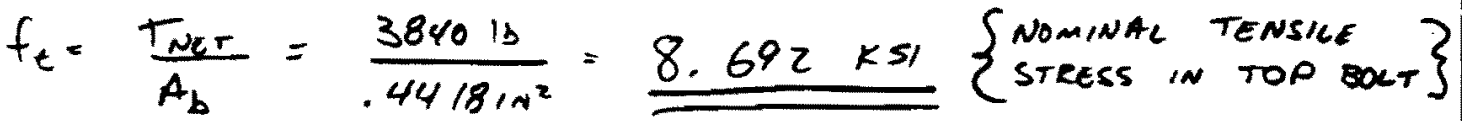

SUMMARY

TENSION DUE TO BENDING:

$$
f_{t}=8.7 \mathrm{ksi}<F_{t}=44 \mathrm{ksi} \text { or }
$$

SHEAR:

$f_{v}, .213 \mathrm{ks}, \ll F_{v}=175 \mathrm{ks}$ ok 
NODE 288

A. KUWAZAK

$4 / 15 / 97$

C 3

REACTION AT \& BOLT PATTERN:
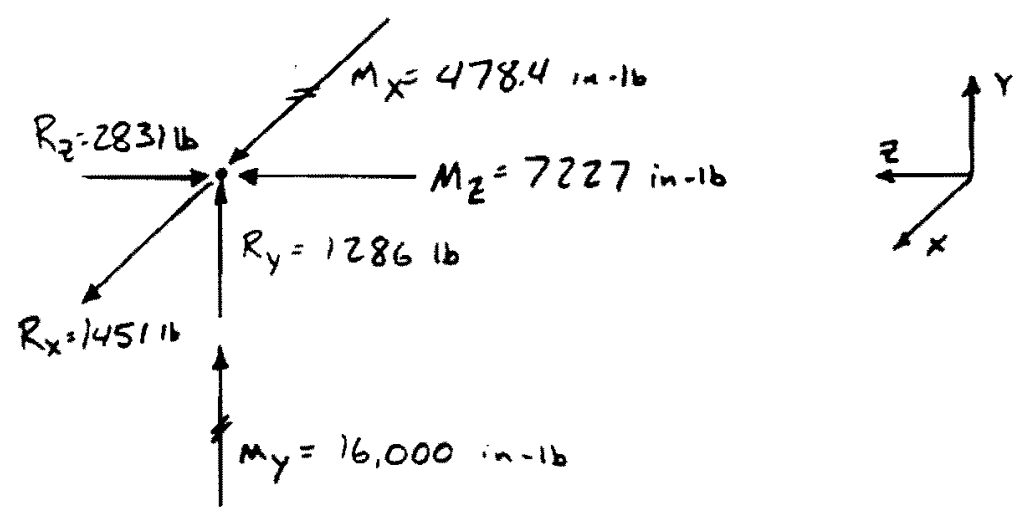

ELASTIC method (FAstener Group anAlysis):
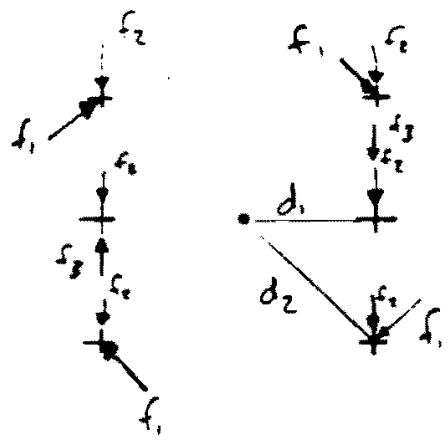

$$
\begin{aligned}
& d_{1}=2.75^{\circ} \\
& d_{2}=3.72^{\prime \prime}
\end{aligned}
$$

PROPORTIONAL SHARE OF $M_{x}$ :

$$
\frac{M_{x}}{\sigma_{\text {foremen }}}=\frac{478.4 i,-1 b}{6}=80 \mathrm{in-1b}=\mu_{x}^{\prime}
$$

EVALUATE $f_{1}:$

$$
\begin{aligned}
& 4 f_{1}\left(d_{2}\right)=M_{x}^{\prime} \\
& f_{1}=\frac{M_{x}^{\prime}}{4 d_{2}}=\frac{80 \text { in -mb }}{4(3.72 \mathrm{mn})}=5.4 \mathrm{~kb} \\
& f_{1 y}=f_{1} \sin 45=3.8=f_{1 x}
\end{aligned}
$$

EVALUATE $f_{3}$ :

$$
\begin{aligned}
& 2 f_{3}\left(d_{1}\right)=M_{x}^{\prime} \\
& f_{3}=\frac{M_{x}^{\prime}}{2 d_{1}}=\frac{80 \text { in -lb }}{2(2.75 m)}=14.5 \mathrm{lb}
\end{aligned}
$$


A. KUWAZAK:

$4 / 15 / 97$

C 4

REACTION $R_{y}$ :

$$
f_{2}=\frac{R_{y}}{6}=\frac{1286 \mathrm{Lb}}{6}=214 \mathrm{lb}
$$

MAX. SHEAR LOAD PER FASTENER:

$$
\begin{aligned}
& f_{\text {Singe }}=\sqrt{\left(f_{1 X}\right)^{2}+\left(f_{1 y}+f_{2}\right)^{2}}=21710 \\
& \text { OR } \\
& f_{\text {SARA R }}=\sqrt{\left(f_{2}+f_{3}\right)^{2}}=229 \mathrm{~b}
\end{aligned}
$$

TENSION FROM BENDING MOMENT (INITIAL TENDON)

$$
f_{b i}=\frac{\Sigma T_{i}}{b d}=2625 \text { psi }
$$

TENSILE STRESS

$$
f_{t b}=\frac{6 M}{b d^{2}}=\frac{6(7227 \mathrm{in}-16)}{(8 . n)^{8, n)^{2}}} \cdot 85 \mathrm{pl}
$$

No further CALCS are neEDED. nODE 288 CONNECTION STRESSES ARE LOWER THAN NODE 1 CONIEETTONS. THEAEFXE NODE 288 CONNECTIONS ARE GOOD. 
NODE 26

A. KuWAzAKI

$4 / 15 / 97$

$C 5$

All fasteners weE to withstand Ry /26 1478 lbs.

$$
\frac{R_{Y 16}}{6}=\frac{147816}{6} \cdot .25 \mathrm{kIP} / \mathrm{BOCT}
$$

AllOWABLE LOAD FROM TARIE $1-D: 7.7$ KIPS.

- Since the calculated load is less then the

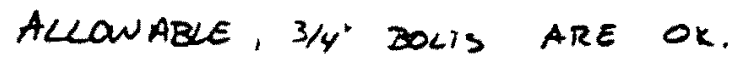

- THE NODE 313 connection reactions Dominate OVER THE NODE 26 REACTIONS.

NODE 313

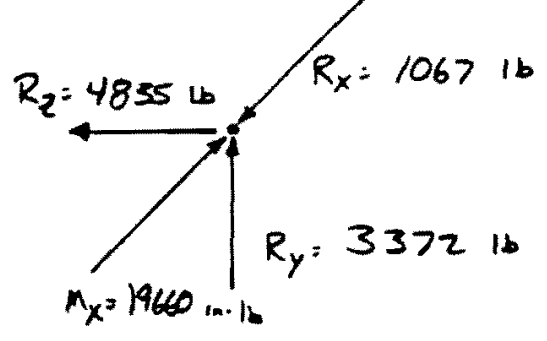

TENSION FROM DENDNG MOMENT CONSIDERING INITIAL TENSION

$$
S_{b i}=\frac{\sum T_{i}}{b d}=\frac{28000 \mathrm{lb}(4)}{(3.95, \mathrm{~N})(4 \mathrm{n})} \cdot 2.025 \mathrm{mi}
$$

TENSILE STRESS DUE TO MOMENT

$$
\begin{aligned}
& f_{t b}=\frac{6 \mu}{b d^{2}}=\frac{6\left(19,660 \mathrm{in}-1 b_{s}\right)}{(3.95, n)(14, N)^{2}}=152 \mathrm{ps} \\
& f_{t b}<f_{b i} \rightarrow 152 \text { psi }<2,025 \text { psi ok } \\
& T_{N E T}=f_{E b} b_{P}=(152 \mathrm{psi})(3.95 \mathrm{NN})\left(Z_{\mathrm{NN}}\right)=1201 \mathrm{~b} \\
& f_{t}=\frac{T_{\text {NET }}}{A_{D}}=\frac{1201 \mathrm{lb}}{.4418 \mathrm{~N}^{2}}, 2.72 \mathrm{ks}
\end{aligned}
$$


A. KuWAZAK,

$4 / 15 / 97$

66

SHEAR COMPONENT(NOOE $3 / 3$ ):

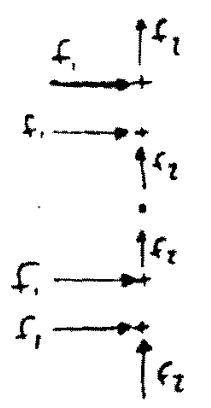

$$
\begin{aligned}
& f_{1}=\frac{R_{x}}{4}=\frac{1067 \mathrm{~b}}{4}=267 \mathrm{lb} \\
& f_{2}=\frac{R_{y}}{4}=\frac{3372 \mathrm{~b}}{4}=843 \mathrm{lb}
\end{aligned}
$$

$$
\begin{aligned}
& v=\frac{\sqrt{(1067)^{2}+(3372)^{2}}}{4}=884 \mathrm{~kb} / \mathrm{BOTT} \\
& f_{V}=\frac{884 \mathrm{bb}}{.4418 \mathrm{~N}^{2}}-2001 \mathrm{psi}
\end{aligned}
$$

SUMmARY

tension due to Bending:

$$
f_{t}=2.72 \mathrm{ks} 1<F_{t}=44 \mathrm{ks} 1 \text { or }
$$

SHEAR:

$$
f_{v}=2.0 \mathrm{ks} 1<F_{v}=17.5 \mathrm{ks} 1 \text { ok }
$$




\section{BIBLIOGRAPHY}

1. American Institute of Steel Construction, Steel Construction Manual, American Institute of Steel Construction, Illinois, 1980.

2. Salmon, G. Charles and Johnson, E. John, Steel Structures: Design and Behavior, $2^{\text {od }}$ Edition. Harper and Row, Publishers, New York, 1980. 